\title{
Biomarker Profiling of Microbial Mats in the Geothermal Band of Cerro Caliente, Deception Island (Antarctica): Life at the Edge of Heat and Cold
}

\author{
María Ángeles Lezcano, ${ }^{1}$ Mercedes Moreno-Paz, ${ }^{1}$ Daniel Carrizo, ${ }^{2}$ Olga Prieto-Ballesteros, ${ }^{2}$ \\ Miguel Ángel Fernández-Martínez, Laura Sánchez-García, ${ }^{1}$ Yolanda Blanco, ${ }^{1}$ Fernando Puente-Sánchez, ${ }^{3}$ \\ Graciela de Diego-Castilla, Miriam García-Villadangos, ${ }^{1}$ Alberto G. Fairén,, ${ }^{2,4}$ and Víctor Parro ${ }^{1}$
}

\begin{abstract}
Substrate-atmosphere interfaces in Antarctic geothermal environments are hot-cold regions that constitute thin habitable niches for microorganisms with possible counterparts in ancient Mars. Cerro Caliente hill in Deception Island (active volcano in the South Shetland Islands) is affected by ascending hydrothermal fluids that form a band of warm substrates buffered by low air temperatures. We investigated the influence of temperature on the community structure and metabolism of three microbial mats collected along the geothermal band of Cerro Caliente registering $88^{\circ} \mathrm{C}, 8^{\circ} \mathrm{C}$, and $2^{\circ} \mathrm{C}$ at the time of collection. High-throughput sequencing of small subunit ribosomal ribonucleic acid (SSU rRNA) genes and Life Detector Chip (LDChip) microarray immunoassays revealed different bacterial, archaeal, and eukaryotic composition in the three mats. The mat at $88^{\circ} \mathrm{C}$ showed the less diverse microbial community and a higher proportion of thermophiles (e.g., Thermales). In contrast, microbial communities in the mats at $2^{\circ} \mathrm{C}$ and $8^{\circ} \mathrm{C}$ showed relatively higher diversity and higher proportion of psychrophiles (e.g., Flavobacteriales). Despite this overall association, similar microbial structures at the phylum level (particularly the presence of Cyanobacteria) and certain hot- and cold-tolerant microorganisms were identified in the three mats. Daily thermal oscillations recorded in the substrate over the year $\left(4.5-76^{\circ} \mathrm{C}\right)$ may explain the coexistence of microbial fingerprints with different thermal tolerances. Stable isotope composition also revealed metabolic differences among the microbial mats. Carbon isotopic ratios suggested the Calvin-Benson-Bassham cycle as the major pathway for carbon dioxide fixation in the mats at $2^{\circ} \mathrm{C}$ and $8^{\circ} \mathrm{C}$, and the reductive tricarboxylic acid cycle and/or the 3-hydroxypropionate bicycle for the mat at $88^{\circ} \mathrm{C}$, indicating different metabolisms as a function of the prevailing temperature of each mat. The comprehensive biomarker profile on the three microbial mats from Cerro Caliente contributes to unravel the diversity, composition, and metabolism in geothermal polar sites and highlights the relevance of geothermal-cold environments to create habitable niches with interest in other planetary environments. Key Words: Deception Island - Cerro CalienteGeothermal-Microbial mat structure-Microbial metabolism-Biomarker. Astrobiology 19, 1490-1504.
\end{abstract}

\section{Introduction}

G EOTHERMAL POLAR ENVIRONMENTS represent extreme habitats for microbial communities in which thermal adaptation is crucial for their survival and growth (Vogt et al., 1997; Dutta and Chaudhuri, 2010; Reed et al., 2013). Antarctica harbors a combination of glaciers and geothermal activity from which originate ice-free terrains due to under- ground magma heat (Herbold et al., 2014). These geothermal sites in Antarctica result into hotspots of diversity and, during past glaciations, had a relevant role as long-term refugia with favorable microclimate conditions for microorganisms and plants (Fraser et al., 2014).

Geothermal environments are also hypothesized to be one of the scenarios wherein the origin of life took place on Earth by providing the hydration/dehydration cycle conditions

Departments of ${ }^{1}$ Molecular Evolution and ${ }^{2}$ Planetology and Habitability, Centro de Astrobiología (CSIC-INTA), Madrid, Spain.

${ }^{3}$ Department of Systems Biology, Centro Nacional de Biotecnología, CSIC, Madrid, Spain.

${ }^{4}$ Department of Astronomy, Cornell University, Ithaca, New York, USA.

(C) María Ángeles Lezcano et al., 2019; Published by Mary Ann Liebert, Inc. This Open Access article is distributed under the terms of the Creative Commons License (http://creativecommons.org/licenses/by/4.0), which permits unrestricted use, distribution, and reproduction in any medium, provided the original work is properly credited. 
required for molecular self-assembly into membranous compartments (Deamer and Georgiou, 2015), and sustaining the inorganic ion requirements of protocells (Mulkidjanian et al., 2012). Despite the existence of different hypotheses for explaining the origin of life on Earth, such as the submarine hydrothermal vents theory (Russell, 2018), the possibility of a geothermal land-based life emergence strengthens the astrobiological relevance of the terrestrial geothermal sites (Van Kranendonk et al., 2017). Therefore, geothermal systems and their associated microbiology on Earth may contribute to decipher extant or extinct life in other planetary bodies (McKay and Stoker, 1989).

At present, Antarctic geothermal environments are associated with four currently active volcanoes: three continentalMt. Erebus, Mt. Melbourne, and Mt. Rittman; and one maritime- Deception Island (Herbold et al., 2014). Particularly, Deception Island is an active stratovolcano from the South Shetlands Islands (located in the Bransfield Basin) that harbors both extremely cold and hot habitats (Smellie and López-Martínez, 2002). The island is ring shaped with a central flooded caldera and possesses a number of hydrothermal vents due to the interaction of water with hot ascending magmas (Rey et al., 1995; Somoza et al., 2004). Nearly all current geothermal sites in Deception Island are originated from recent past (1967-1970) volcanic events (Baker and McReath, 1971; Rey et al., 1995) and are thus relatively young (Herbold et al., 2014). This recent volcanic activity confers to Deception Island a remarkable environmental value for ecological studies, such as organisms colonization, singularity, and ecological dynamics (Cameron and Benoit, 1970; Barnes et al., 2008), and thus certain sites of the island are comprised within the Antarctic Specially Protected Areas (ASPA) (ATS, 2012).

One of the most relevant ASPA sites in Deception Island is Cerro Caliente, a $107 \mathrm{~m}$ high hill (Cerro, in Spanish) with a unique microphyte associated with the geothermal activity (ATS, 2012). The geothermal activity in Cerro Caliente comprises a narrow band of substrate affected by hydrothermal fluids ascending from a fault and extending along ca. $40 \mathrm{~m}$ length and $3 \mathrm{~m}$ wide along the summit ridge (ATS, 2012). Water vapor, carbon dioxide $\left(\mathrm{CO}_{2}\right)$, and minor proportions of hydrogen sulfide and sulfur dioxide, at temperatures that reach up to $100^{\circ} \mathrm{C}$, characterize the fumarolic gases and determine the ground geochemistry (Caselli et al., 2004, 2007). Therefore, the co-occurrence of snow and geothermal activity (high temperature and water upwelling) in Cerro Caliente maintains relatively steady liquid water availability over the year (Logan and Allan, 2008) and supplies nutrients to the surface, thus favoring the growth of microbial mats.

Unlike other geothermal areas worldwide (e.g., Miller et al., 2009; Wang et al., 2013; Sharp et al., 2014), the microbial community present in Deception Island is weakly characterized, with few studies focused on the isolation of thermophilic and psychrophilic bacteria (Carrión et al., 2011; Muñoz et al., 2011; Bendia et al., 2018a) with potential use for biotechnological applications (Flores et al., 2018). The coexistence of microorganisms with different thermal and metabolic traits (ammonia oxidation, sulfur reduction, and methanogenesis) was attributed to the steep physicochemical gradients (temperature and geochemical) across the island (Fermani et al., 2007; Bendia et al., 2018b, 2018a). Submarine samples from the flooded caldera also showed coexistence of thermophilic and psychrophilic archaea (Amenábar et al., 2013). Specifically, in the geothermal band of Cerro Caliente, the scarcity of studies on the composition and metabolism of the microbial communities is particularly accentuated. Llarch et al. (1997) isolated a thermophilic bacterium from the genus Bacillus sp. in the fumarolic water from Cerro Caliente, and Fermani et al. (2007) reported the presence of filamentous cyanobacteria and diatoms in microalgal communities growing on the warm substrate. However, little is known about the community structure and metabolisms of the microbial mats thriving in such particular geothermal site.

In this study, the community structure and major metabolic traits were characterized for three microbial mats distributed along the geothermal band of Cerro Caliente. Specifically, we explored the influence of temperature on the bacterial, archaeal, and eukaryotic community structure, and on the carbon and nitrogen metabolism, in three microbial mats registering surface temperatures of $88^{\circ} \mathrm{C}, 8^{\circ} \mathrm{C}$, and $2^{\circ} \mathrm{C}$ at the time of collection and spanned for ca. $10 \mathrm{~m}$ long in the Cerro Caliente geothermal summit. To achieve this, we applied isotope-ratio mass spectrometry (IRMS), fluorescence microarray immunoassays, and high-throughput DNA sequencing to investigate the distribution of isotopic $\left(\delta^{13} \mathrm{C}\right.$ and $\delta^{15} \mathrm{~N}$ ) and molecular (antibodies and 16S and 18S rRNA genes) biomarkers in the microbial mats.

\section{Materials and Methods}

\subsection{Field site and sampling}

Sampling was conducted on February 2, 2012 (i.e., austral summer) in the geothermal summit of Cerro Caliente, a hill located in Deception Island (Fig. 1) formed by pyroclastic deposits of subalkaline andesitic basalt. Three microbial mats with different surface temperatures and extending along ca. $10 \mathrm{~m}$ were sampled. The temperature of each mat was measured at $1 \mathrm{~cm}$ below the surface with an electronic thermometer, resulting in $88^{\circ} \mathrm{C}$ for Mat- $1,8^{\circ} \mathrm{C}$ for Mat-2, and $2{ }^{\circ} \mathrm{C}$ for Mat-3. Geographical coordinates of Mat- 1 and Mat-2 were $62^{\circ} 58^{\prime} 24.6^{\prime \prime} \mathrm{S}$ and $60^{\circ} 42^{\prime} 44.3^{\prime \prime} \mathrm{W}$ and those for Mat-3 were $62^{\circ} 58^{\prime} 24.6^{\prime \prime} \mathrm{S}$ and $60^{\circ} 42^{\prime} 45.1^{\prime \prime} \mathrm{W}$. In addition, a ground sample registering $98^{\circ} \mathrm{C}$ was collected from the subsurface $(0-20 \mathrm{~cm})$ at $62^{\circ} 58^{\prime} 25.6^{\prime \prime} \mathrm{S}$ and $60^{\circ} 42^{\prime} 40.2^{\prime \prime} \mathrm{W}$. The three microbial mats and the ground sample were collected using a sterile spatula, introduced in sterile WhirlPack sample bags and stored at $-20^{\circ} \mathrm{C}$ until laboratory analyses. Close to the ground sampling spot, a thermocouple was placed at $2.5 \mathrm{~cm}$ depth for monitoring the ground temperature every $4 \mathrm{~h}$ during a year. The atmospheric temperature was constant during sampling $\left(\sim 0^{\circ} \mathrm{C}\right)$.

\subsection{Mineralogy and physicochemical analysis of the substrate}

The mineralogical characterization of the ground sample was performed with X-ray diffraction (XRD) and infrared spectroscopy techniques. XRD of the powdered ground sample was performed by using a Seifert 3003 TT (GE Inspection Technologies $\mathrm{GmbH}$, Germany) with $\mathrm{Cu} K \alpha$ anode $(\lambda=1.542 \AA)$. The $\mathrm{X}$-ray generator was set to an acceleration voltage of $40 \mathrm{kV}$ and a filament emission of $40 \mathrm{~mA}$. The 
A

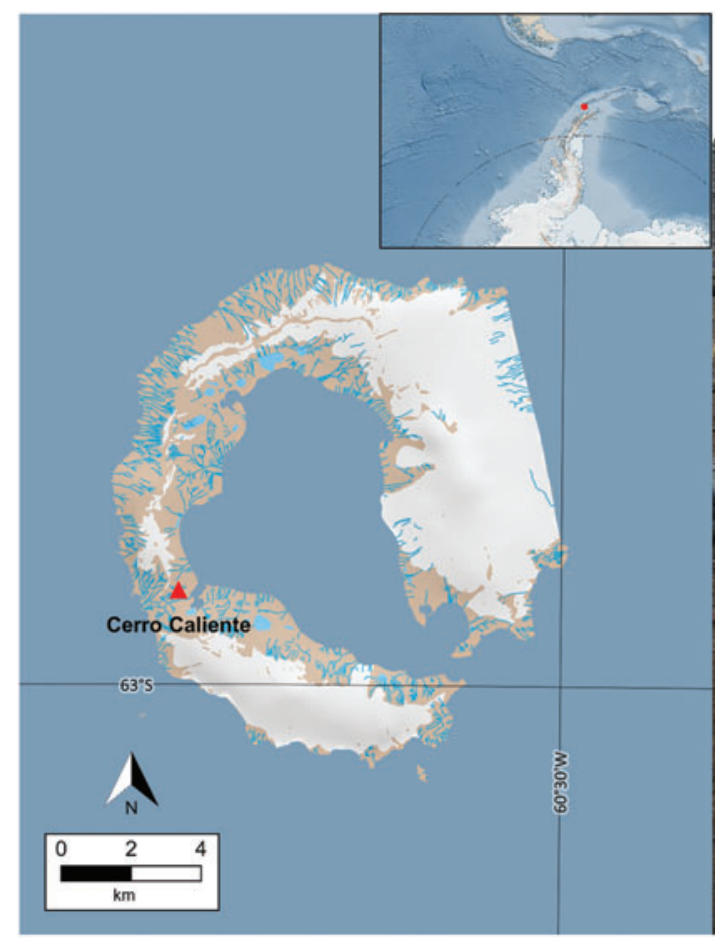

B

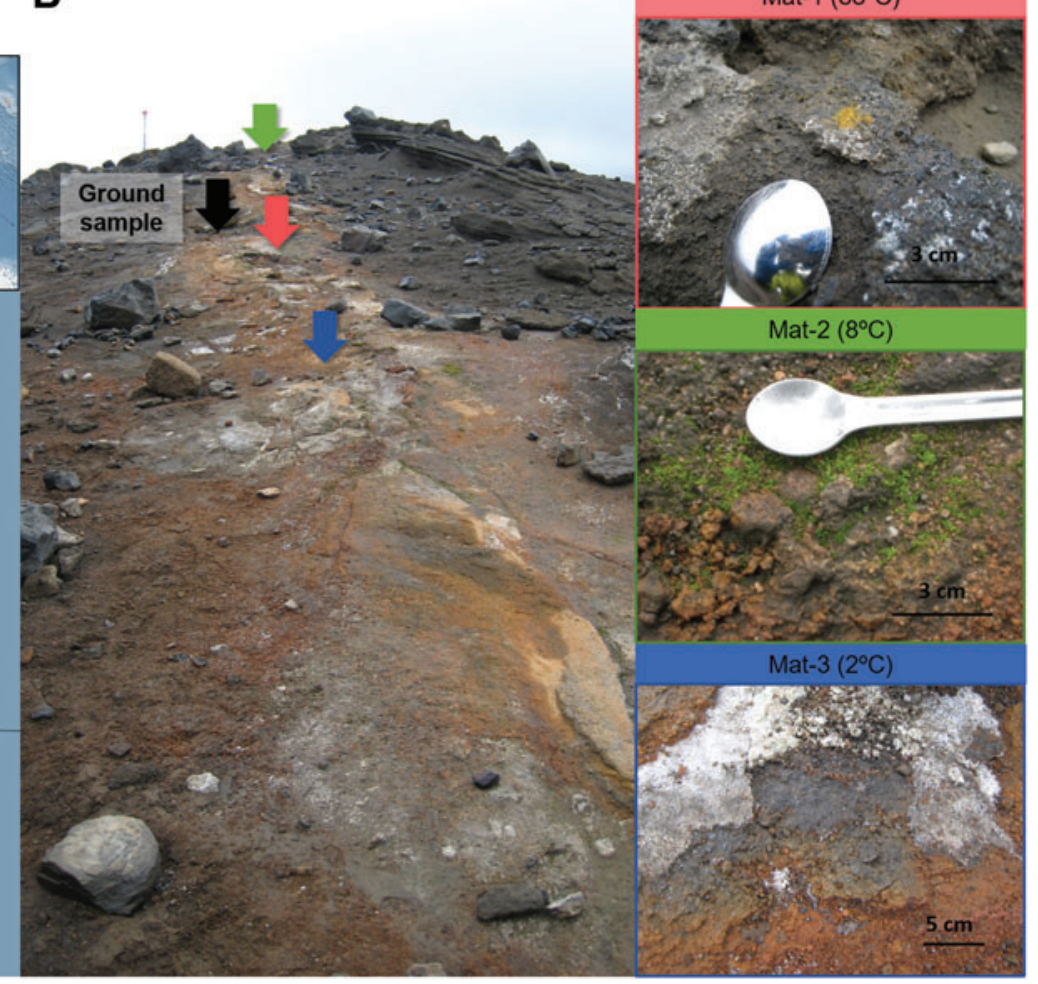

FIG. 1. Sampling location at Cerro Caliente, Deception Island. Map showing Deception Island close to the Antarctic Peninsula (A), and pictures showing the sampling sites at Cerro Caliente and the aspect of the microbial mats (B). Black arrow indicates the site for ground sample and color arrows indicate the location for the microbial mat samples. Source of the map: Quantartica (Matsuoka et al., 2018).

range of measurement was from $5^{\circ}$ to $60^{\circ}$, with a scanning step size of $0.1^{\circ}$. In addition, the oriented aggregate sample was used to determine the fine grain mineralogy. The powdered sample was also analyzed with a Thermo Nicolet Nexus spectrometer (Nicolet Instrument Corporation, Madison, WI) working with a Diffuse Reflection Praying Mantis (Harrick Scientific, New York, NY), DTGS-KBr detector, and $\mathrm{XT}-\mathrm{KBr}$ beamsplitter. Measurements were performed with 128 scans and a spectral resolution better than $4 \mathrm{~cm}^{-1}$.

Concentration of nitrate $\left(\mathrm{NO}_{3}{ }^{-}\right)$, nitrite $\left(\mathrm{NO}_{2}{ }^{-}\right)$, phosphate $\left(\mathrm{PO}_{4}{ }^{3-}\right)$, and sulfate $\left(\mathrm{SO}_{4}{ }^{2-}\right)$ in the ground sample was determined in triplicates by ion chromatography (IC). One gram of substrate was suspended in $12 \mathrm{~mL}$ of IC-grade water, vortexed for 1 to $2 \mathrm{~min}$, and then incubated with agitation overnight. Then, the sample was centrifuged $(4000 \times g$ for $10 \mathrm{~min}$ at room temperature) and filtered through a $0.22 \mu \mathrm{m}$ PTFE filter (Sartorius, Göttingen, Germany) to remove mineral particles. The supernatant was loaded in a Metrohm 861 Advanced Compact Ion Chromatographer (Metrohm AG, Herisau, Switzerland) by an automatic loader and chromatographic separation was performed in a Metrosep A supp 7-250 column (Metrohm AG). The mobile phase consisted of $3.6 \mathrm{mM}$ sodium carbonate with a flow rate of $0.7 \mathrm{~mL} / \mathrm{min}$. Quantification of anions was performed by plotting a 6-point calibration curve from each commercial anion standard (Sigma-Aldrich, St. Louis, MO). $\mathrm{pH}$ was measured in a suspension of substrate: Milli-Q water (1:2.5) with Eutech pH700 (Thermo Fisher Scientific).

\subsection{Isotope characterization of the microbial mats}

The stable isotopic composition of total organic carbon (TOC) $\left(\delta^{13} \mathrm{C}\right)$ and total nitrogen (TN) $\left(\delta^{15} \mathrm{~N}\right)$ of the bulk microbial mats was measured in triplicates by isotope ratio mass spectrometry (IRMS) with a MAT 253 (Thermo Fisher Scientific) following the analytical methods of the US Geological Survey (Révész et al., 2012). About $0.5 \mathrm{~g}$ of dry weight biomass of each mat was grounded and homogenized using a mortar and pestle, and carbonates were removed with the addition of $\mathrm{HCl}(3 \mathrm{M})$. Then, each mat sample was split into three and replicates were equilibrated for $24 \mathrm{~h}$, adjusted to neutral $\mathrm{pH}$ with ultrapure water, and dried in an oven $\left(50^{\circ} \mathrm{C}\right)$ until constant weight. The $\delta^{13} \mathrm{C}$ and $\delta^{15} \mathrm{~N}$ values were reported in the standard per mil notation using three certified standards (USGS41, IAEA-600, and USGS40) with an analytical precision of $0.1 \%$. TOC (\%) and TN (\%) contents were measured during stable isotope measurements using Flash HT Elemental Analyzer (Thermo Fisher Scientific).

\subsection{DNA extraction of the microbial mats}

Genomic DNA of the microbial mats was extracted by using DNeasy PowerBiofilm Kit (QIAGEN, Hilden, Germany) following manufacturer's instructions. Genomic DNA of each microbial mat consisted in two separated extractions of $0.5 \mathrm{~g}$ combined at the elution step to increase DNA concentration for sequencing analysis. A negative control of the kit was also performed. DNA concentrations were determined in a NanoDrop ND 1000 spectrophotometer (Thermo Fisher Scientific) and stored at $-20^{\circ} \mathrm{C}$ until sequencing analysis. 


\section{5. $16 S$ rRNA and $18 S$ rRNA genes sequencing and data analysis}

Bacterial, archaeal, and eukaryotic communities from microbial mats were identified by the construction of pairedend amplicon libraries on an Illumina MiSeq platform (Illumina Inc., San Diego, CA). Bacterial 16S rRNA V3-V4 hypervariable gene region was amplified with the primer pair 341-F/805-R (Herlemann et al., 2011), archaeal 16S rRNA V2-V3 hypervariable gene region was amplified with the primer pair Arch1F/Arch1R (Cruaud et al., 2014), and eukaryotic 18S rRNA V4-V5 hypervariable gene region was amplified with the primer pair 563F/1132R (Hugerth et al., 2014). Polymerase chain reaction and Illumina MiSeq sequencing were carried out at the Genomic Service in Madrid Science Park Foundation (FPCM).

Raw sequences were processed in MOTHUR software v.1.40.5 (Schloss et al., 2009), using a custom script based on MiSeq SOP (Kozich et al., 2013). In brief, reads below a minimum number of base pairs ( $\leq 400 \mathrm{bp}$ for bacteria, $\leq 300 \mathrm{bp}$ for archaea, and $\leq 550 \mathrm{bp}$ for eukarya), with ambiguous nucleotide identities and/or homopolymers longer than $8 \mathrm{bp}$, singletons, and putative chimeras were removed from subsequent analyses. Remaining sequence reads (i.e., 531,261 for bacteria, 295,261 for archaea, and 271,506 for eukarya) were then clustered into operational taxonomic units (OTUs) at the $97 \%$ similarity level. Gene library sizes of the mat samples were normalized to the lesser number of sequences (i.e., 124,044 for bacteria, 81,287 for archaea, and 56,561 for eukarya) by random selection. Sequencing depth for each sample was tested by means of rarefaction curves constructed by using iNEXT Online: software for the interpolation and extrapolation of species diversity (Chao et al., 2016).

Taxonomic assignations were performed by comparing OTU's representative sequences with RDP database (RDP reference files v.16; release 11; Cole et al., 2014). OTUs assigned to "cyanobacteria/chloroplast" were further compared with NCBI GenBank, EMBL, Greengenes, and SILVA databases for more precise cyanobacteria taxonomic identification. To avoid false positives, singletons, sequences that were assigned to nonbacterial, nonarchaeal, or noneukaryotic entities in their respective gene libraries, and OTUs that were more represented in the negative controls than in two out of three mat samples, were removed from the analysis. Thus, database screenings discarded $7.5 \%, 66.2 \%$, and $19.8 \%$ of the bacterial, archaeal, and eukaryotic gene libraries, respectively. Raw sequence reads were deposited at the NCBI Sequence Read Archive (SRA) under the BioProject ID PRJNA549255.

\subsection{Fluorescent sandwich microarray immunoassays with Life Detector Chip}

Microbial mats were analyzed by fluorescent sandwich microarray immunoassays (FSMIs) using Life Detector Chip (LDChip), an antibody microarray-based biosensor (Parro et al., 2008; Sánchez-García et al., 2018). The LDChip used in this study contained 187 polyclonal antibodies (purified immunoglobulin $\mathrm{G}$ [IgG] fraction) designed to identify bacteria from main phyla (e.g., Proteobacteria, Actinobacteria, Firmicutes, Bacteroidetes, and Cyanobacteria), endospores and exospores from Gram-positive bacteria and archaea (halophilic, methanogenic, and thermophilic), biological polymers (including lipo/exo-polysaccharides), and conserved proteins and peptides involved in key metabolisms (e.g., nitrogen fixation, nitrogen and sulfur reduction, and iron homeostasis) (Rivas et al., 2008; Parro et al., 2011). The antibodies used in this study are described in Supplementary Table S1. The IgG fraction of each antibody was printed on the surface of epoxyactivated glass slides as described in the study of Blanco et al. (2012). For the FSMI, all IgGs were fluorescently labeled with Alexa 647 fluorochrome (Molecular Probes), titrated, and used in a mixture to reveal the immunoreactions, as described in the study of Rivas et al. (2008) and Blanco et al. (2017).

The procedure for the LDChip analysis was described in detail in the work of Blanco et al. (2017). In brief, $\sim 0.5 \mathrm{~g}$ of each mat was resuspended in $2 \mathrm{~mL}$ of TBSTRR buffer $(0.4 \mathrm{M}$ Tris- $\mathrm{HCl} \mathrm{pH}$ 8, 0.3 M NaCl, 0.1\% Tween 20), ultrasonicated, and filtered through $5 \mu \mathrm{m}$ filters to be used as a multianalytecontaining sample for the FSMI. LDChip images were analyzed and quantified by GenePix Pro Software (Molecular Devices, Sunnyvale, CA). Final fluorescence intensity $(F)$ of each antibody was calculated as described in the study of Rivas et al. (2011) and Blanco et al. (2012). In addition, a cutoff value was applied to all spots to minimize false positives. This cutoff value was the first interval of $F$ with an accumulated frequency $>80 \%$ and an increase $<10 \%$. The output fluorescence data were normalized, attending to the number of positive probes per taxonomic/metabolic group and to total microarray fluorescence values (He et al., 2007).

\subsection{Statistical analysis}

Correspondence analysis (CA) was performed with CANOCO5 v.5.04 software (Microcomputer Power, Ithaca, $\mathrm{NY}$ ) to explore the relationship between the log-transformed relative abundances of bacterial, archaeal, and eukaryotic taxonomic orders in the three microbial mats. Richness (number of OTUs) and Shannon-Weiner $\left(\mathrm{H}^{\prime}\right)$, Simpson, and evenness indices were calculated for the bacterial, archaeal, and eukaryotic community compositions by using the $\mathrm{R}$ package "vegan" v.2.4-3 (Oksanen et al., 2017). Dissimilarities between microbial mat communities were estimated using Bray-Curtis distances.

\section{Results}

\subsection{Mineralogical and physicochemical characterization of the geothermal substrate}

XRD analysis of the ground sample identified montmorillonite, nontronite, saponite, Na-zeolites, and calcite. The temperature of the ground sample was $98^{\circ} \mathrm{C}$, and the $\mathrm{pH} 7.1$. The concentration of $\mathrm{NO}_{3}{ }^{-}-\mathrm{N}$ was $0.22 \pm 0.15 \mu \mathrm{g} / \mathrm{g}$ and $\mathrm{NO}_{2}{ }^{-}-\mathrm{N}$ was under the limit of detection $(<1 \mathrm{ppb})$. Other anions present in the ground sample were soluble $\mathrm{PO}_{4}{ }^{3-}$-P with $0.29 \pm$ $0.12 \mu \mathrm{g} / \mathrm{g}$ and soluble $\mathrm{SO}_{4}{ }^{2-}-\mathrm{S}$ with $1.39 \pm 1.17 \mu \mathrm{g} / \mathrm{g}$. The ground temperature recorded under the surface oscillated from $4.5^{\circ} \mathrm{C}$ to $76^{\circ} \mathrm{C}$ over the year and showed daily variations, for example, from $24^{\circ} \mathrm{C}$ to $70^{\circ} \mathrm{C}$ on June 15 (Fig. 2). The annual mean, median, and mode temperatures were $27^{\circ} \mathrm{C}, 25^{\circ} \mathrm{C}$, and $21^{\circ} \mathrm{C}$, respectively.

\subsection{Carbon and nitrogen elemental and isotopic composition of the microbial mats}

TOC and TN concentrations varied markedly between mats. Mat-1 showed the largest TOC (4.1\%) and TN $(0.5 \%)$ 


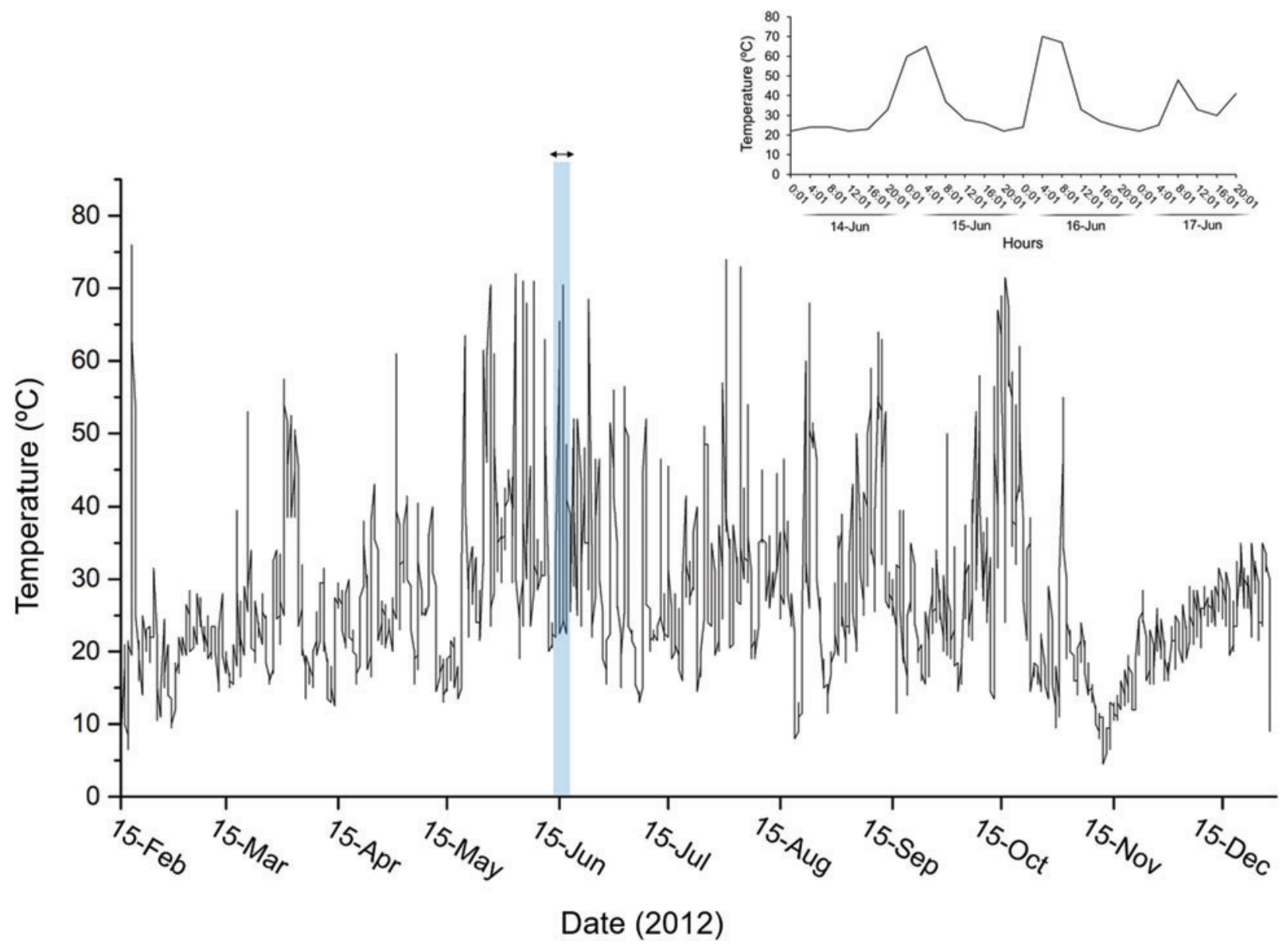

FIG. 2. Ground thermal oscillations at $2.5 \mathrm{~cm}$ depth in the geothermal band of Cerro Caliente over the year 2012 . Temperature was measured with a thermocouple located inside a hole perforated close to the ground sampling point. Upper plot represents a zoom of the temperature oscillations every $4 \mathrm{~h}$ recorded from 14 to 17 June.

concentration (Fig. 3A, B). In contrast, Mat-2 and Mat-3 contained 8-fold and 23-fold lower TOC and TN content than Mat-1, respectively. The lowest TOC $(0.18 \%)$ and TN $(0.02 \%)$ contents were observed in Mat-3.

The $\delta^{13} \mathrm{C}$ isotopic composition varied between the three microbial mats (Fig. 3C), with Mat-2 and Mat-3 showing similar depleted $\delta^{13} \mathrm{C}$ ratios $(-23.9 \%$ and $-21.1 \%$, respectively) in comparison with Mat-1 $(-14.3 \%)$. For $\delta^{15} \mathrm{~N}$, the most enriched ratio was observed in Mat-3 $(-5.3 \%)$, in contrast to the depleted signatures of Mat-2 $(-35.5 \%)$ and Mat-1 (-26.5\%) (Fig. 3D).

\subsection{Bacterial, archaeal, and eukaryotic community structure of the microbial mats}

A total of $531,261,295,261$, and 271,506 high-quality sequence reads were recovered from the three mat samples with the bacterial, archaeal, and the eukaryotic SSU rRNA gene amplicons, respectively. After subsampling, control screening and removal of sequences assigned to nonbacterial, nonarchaeal, or noneukaryotic entities in their respective gene libraries, total OTUs identified at $97 \%$ similarity were 1925 for bacteria, 55 for archaea, and 991 for eukarya.
The analysis of the bacterial community composition showed 21 distinct phyla, among which 16 exhibited relative abundances $>0.5 \%$ in at least one mat (Fig. 4A). The three mat profiles shared $95 \%$ of the bacterial phyla with differences in their relative abundances. Cyanobacteria dominated the taxonomic profiles of Mat-1 (41\%) and Mat-3 (43\%), and showed a lower proportion in Mat-2 (7\%). DeinococcusThermus accounted for $15 \%$ of the total reads in Mat-1, and only accounted for $9 \%$ in Mat-2 and $1 \%$ in Mat-3. Bacteroidetes and Acidobacteria also showed differences across mats, ranging from $\sim 2 \%$ to $\sim 10 \%$ in the three microbial mats. Chloroflexi was present in similar proportions in Mat-1 (2.1\%) and Mat-2 (2.8\%), and Firmicutes and Nistrospirae were mainly identified in Mat-1, with $0.9 \%$ each. The phyla Proteobacteria was the only phyla present with relatively higher abundance in the three mats $(29 \% \pm 8 \%)$.

The archaeal community composition in the three microbial mats showed two different phyla, Thaumarchaeota and Euryarchaeota, and a large fraction of unclassified archaea in Mat-1 (65\%) and Mat-2 (66\%) (Fig. 4B). The phylum Thaumarchaeota, dominated by the order Nitrososphaerales, was equally represented in Mat-1 (35\%) and Mat-2 (34\%), and only accounted for $2 \%$ of the total reads in Mat-3. In contrast, the phylum Euryarchaeota was abundant 

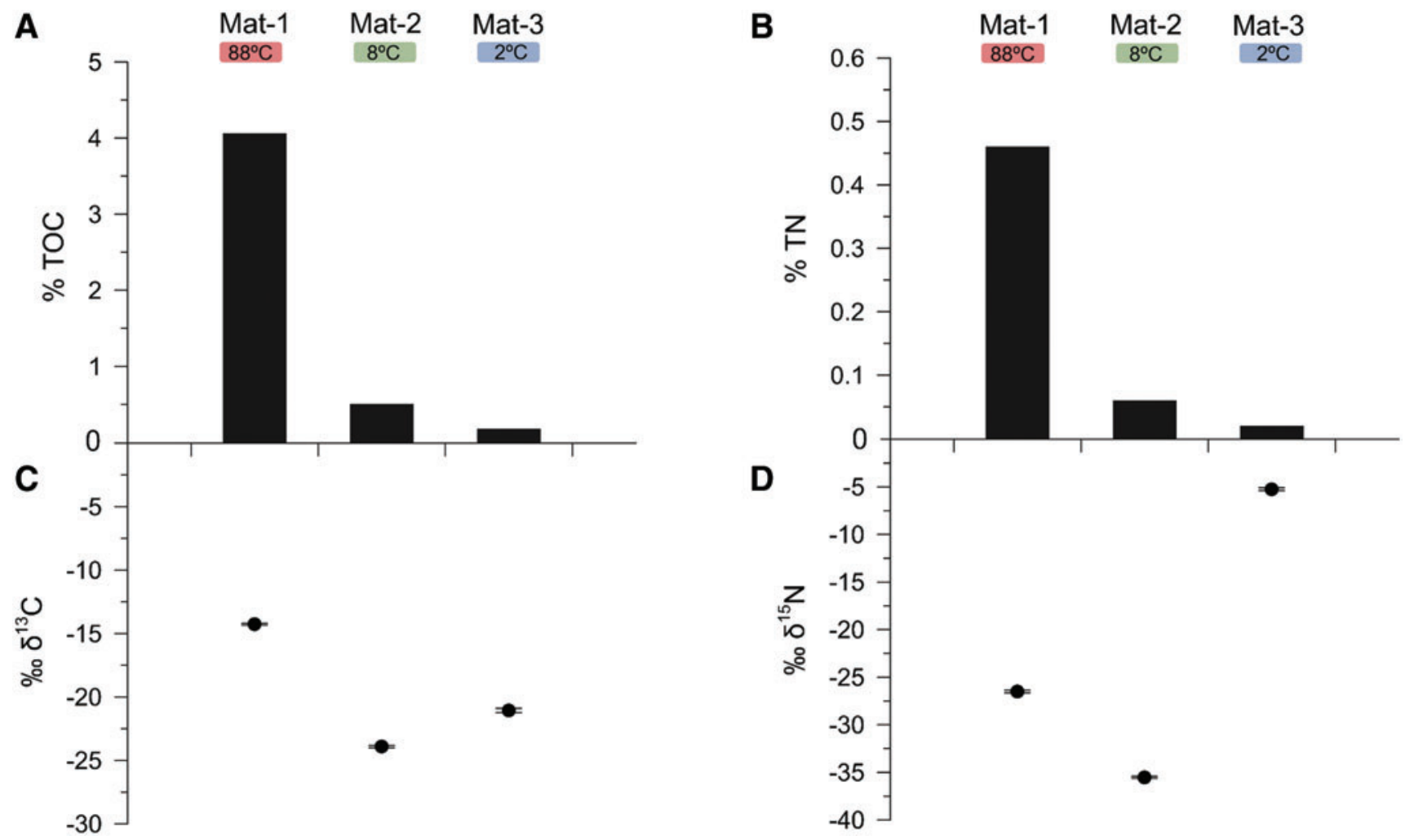

FIG. 3. Carbon and nitrogen composition in the three microbial mats. The plots show (A) TOC (\%) and (B) TN (\%) contents, and $(\mathbf{C})$ isotopic $\delta^{13} \mathrm{C}$ and $(\mathbf{D}) \delta^{15} \mathrm{~N}$ ratios $(\%)$. Error bars indicate standard deviation of triplicates. TN, total nitrogen; TOC, total organic carbon.

in Mat-3 (96\%), and it showed lower proportion in Mat-1 and Mat-2 $(<0.002 \%)$.

The eukaryotic community composition showed 13 different phyla, among which only 5 showed relative abundances $>0.5 \%$ in at least one of the mats (Fig. 4C). Chlorophyta (green algae) and Phragmoplastophyta (Streptophyta) dominated the three mat profiles and were found in different proportions (44$75 \%$ and $11-31 \%$, respectively) across mats. Several fungal taxa were also identified in the three mat samples. Ascomycota and Chytridiomycota accounted for $9 \%$ and $0.11 \%$ of the total sequences in Mat-1, and 2\% and 1\% in Mat-3, respectively. In Mat-2, both phyla were $<0.55 \%$. Phylum Ochrophyta (diatoms, brown algae, and chrysophytes) accounted for $22 \%$ of the total reads in Mat-2.

\subsection{Correspondence analysis of the composition of the microbial communities}

To investigate the relationships between the microorganisms present in the three microbial mats, a CA was performed with the relative abundances of the whole bacterial, archaeal, and eukaryotic data sets at the taxonomic order level of the three microbial mats (Fig. 5).

According to the analyses, most of the bacterial orders showed slight variations in their relative abundances among mats, based on their central location in the plot (Fig. 5A). Still, certain orders showed higher relationship with specific mats. For instance, heat-tolerant bacteria from orders $\mathrm{Kal}$ lotenuales, Bacillales, Thermales, Chthonomonadales, and Gp16 (phylum Acidobacteria) and $\mathrm{NO}_{2}^{-}$-oxidizing bacteria from the order Nitrospirales were more closely associated with Mat-1 (i.e., $88^{\circ} \mathrm{C}$ ) than with the other two mats. In contrast, psychrophilic bacteria from the order Flavobacteriales and Cytophagales were more related to Mat-3 (i.e., $2^{\circ} \mathrm{C}$ ), as well as Pseudomonadales. Unlike this thermal pattern observed in Mat-1 and Mat-3, Mat-2 (i.e., $8^{\circ} \mathrm{C}$ ) showed association with some thermophilic bacteria (Ktedonobacterales), in addition to other groups such as anaerobic iron reducers (Holophagales) or predators (Bdellovibrionalles).

Within the archaeal community, the ammonium-oxidizing order Nitrosopumilales and the phylum Euryarchaeota were mainly associated with Mat-3 (Fig. 5B). The order $\mathrm{Ni}$ trosophaerales and unclassified archaea, however, were present in similar relative abundances in both Mat-1 and Mat-2, thus lacking any relationship with a specific mat.

Within the eukaryotic community, several algae, mosses, and unclassified eukaryotes were in similar proportions in all mats, lacking any relationship with a specific mat (Fig. 5C). In contrast, certain orders showed differences across mats. For instance, the cold-tolerant and lichen-associated fungi Hypocreales and Coniochaetales, the green algae Chlamydomonadales, and the amoeba Shizoplasmodiida were closely related to Mat-1 (i.e., $88^{\circ} \mathrm{C}$ ). The lichen-associated fungi Thelebolales, the yeast Kriegeriales, and the coldtolerant chytrid Rhizophydiales, among other fungi, were closely related to Mat-3 (i.e., $2^{\circ} \mathrm{C}$ ), and the fungi Chytridiomycota and LKM15 (phylum Cryptomycota), diatoms (Bacillariophytina), and green algae (unclassified Chlorophyceae) were related to Mat-2 (i.e., $8^{\circ} \mathrm{C}$ ). 


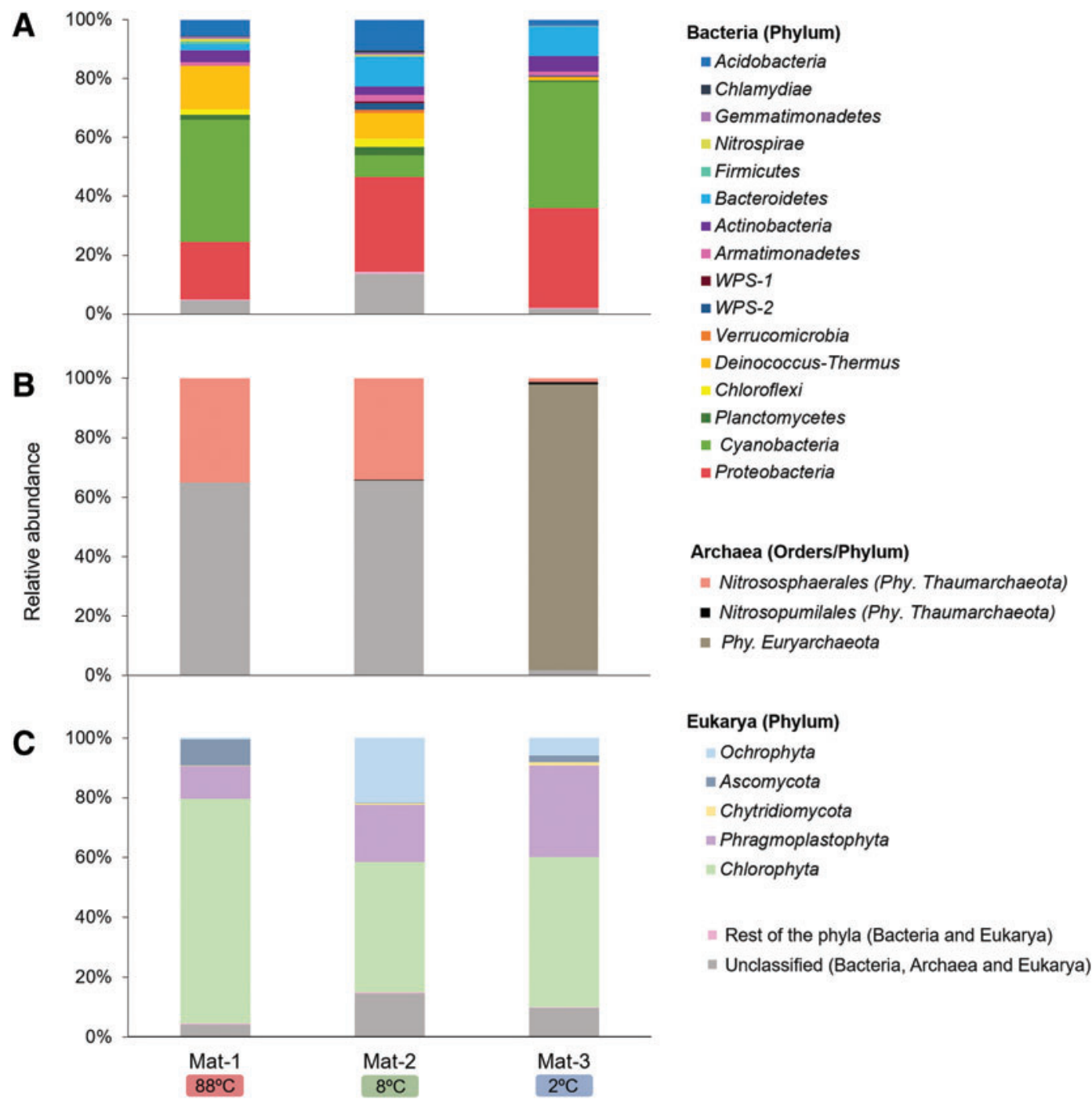

FIG. 4. Microbial community structure of the mat samples in the geothermal band of Cerro Caliente. Total bacterial (A), archaeal (B), and eukaryotic (C) community composition at phylum level identified in terms of relative abundance. In the Archea domain, the order is also represented. The phyla with relative abundances $<0.5 \%$ in the three microbial mats are comprised in the "rest of the phyla" group.

\subsection{Diversity indices}

Richness, Shannon-Wiener, and Simpson diversity indices in the three mats were higher for bacteria and eukarya than for archaea (Table 1). Moreover, differences within communities were found across mats. Bacteria showed the highest diversity and richness values in Mat-2 $\left(\mathrm{H}^{\prime}=5.24\right.$; OTUs = 1214), and the lowest in Mat-1 $\left(\mathrm{H}^{\prime}=3.73\right.$; OTUs $=$ 845). In eukarya, the highest diversity and richness values were found in Mat-2 $\left(\mathrm{H}^{\prime}=2.76\right.$; OTUs $\left.=508\right)$ and Mat-3 $\left(\mathrm{H}^{\prime}=3.30\right.$; OTUs $\left.=480\right)$, and those for archaea were found in Mat-1 $\left(\mathrm{H}^{\prime}=0.84\right.$; OTUs $\left.=45\right)$ and Mat-2 $\left(\mathrm{H}^{\prime}=1.02\right.$; OTUs $=$ 41). Evenness indices indicated that Mat-2 possessed the most equally distributed bacterial (evenness $=0.74$ ) and archaeal (evenness $=0.28$ ) community composition, and Mat-3 possessed the most equally distributed eukaryotic community composition (evenness $=0.53$ ).

Bray-Curtis index showed higher similarity in the microbial community structure between Mat-1 and Mat-2 (0.84 for bacteria, 0.58 for eukarya, and 0.37 for archaea) than both mats with Mat-3 (bacteria, archaea, and eukarya $>0.90$ ) (Table 2). Still, the three mats shared $15 \%$ of the bacterial OTU composition, $6 \%$ of the archaeal OTU composition, and $7 \%$ of the eukaryotic OTU composition.

\subsection{Microbial markers detected by LDChip multiplex immunoassays}

The LDChip detected microbial markers that could be associated with different phylogenetic groups and metabolisms in the mat samples (Fig. 6). For instance, Cyanobacteria was immunodetected in Mat-1 and Mat-3, and was negligible in Mat-2. This is in agreement with the $41 \%, 43 \%$, and $7 \%$ of Cyanobacteria identified in Mat-1, Mat-3, and Mat-2 with the $16 \mathrm{~S}$ rRNA gene analysis, respectively. Proteobacteria (alpha, beta, gamma, and delta classes) was detected with LDChip in the three mats, and showed the highest relative intensity signals in Mat-2 and Mat-3, consistent with the 32\%, 34\%, and $20 \%$ of relative abundance in Mat-2, Mat-3, and Mat-1 with DNA analyses, respectively. Moreover, Deinococcus- 

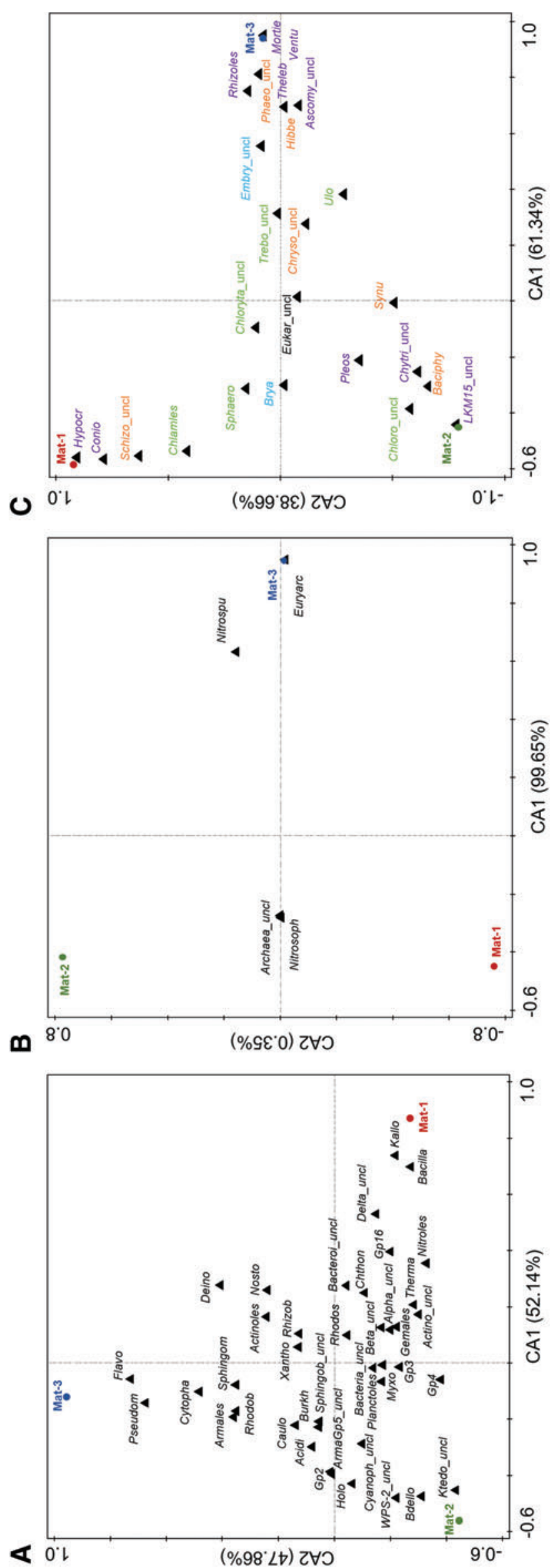

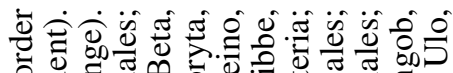

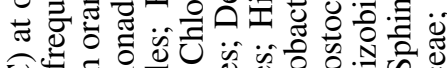

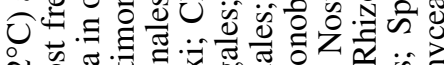
¿े

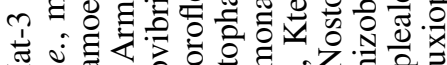
$\Sigma$ 实

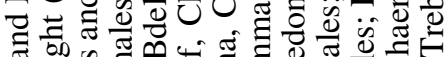
ส.

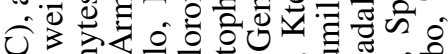

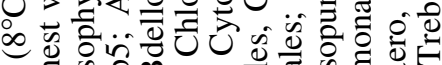
T क्र

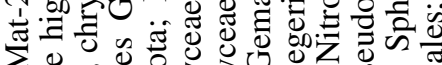

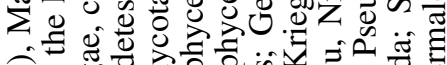
0ิ $\infty$ 宊

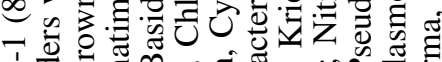

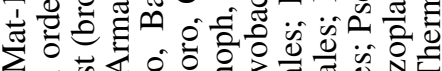

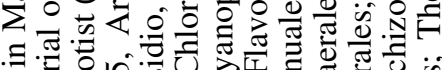

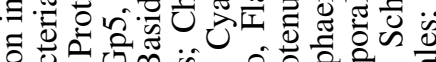

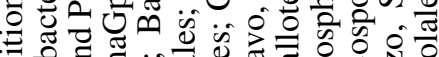

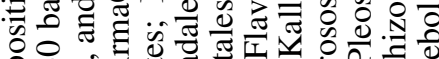

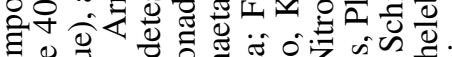

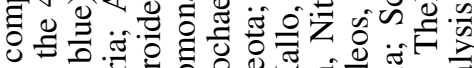

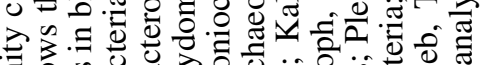

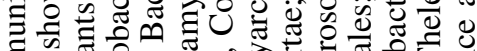

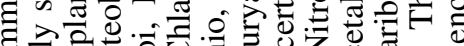

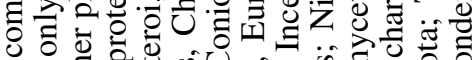
○ $0<\overline{0}$

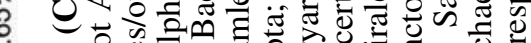

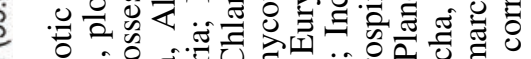
¿

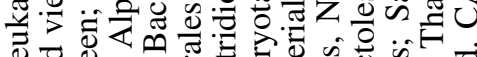

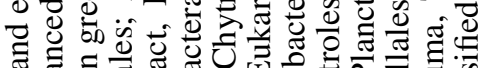

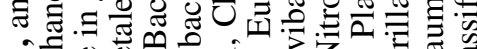

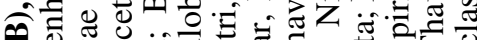

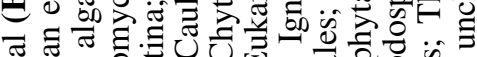
ส

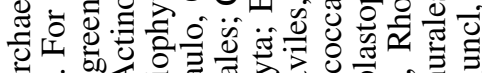

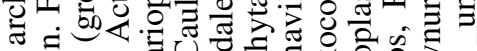

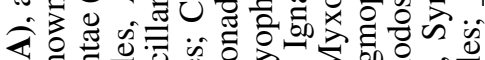

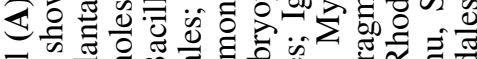

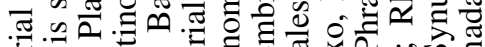

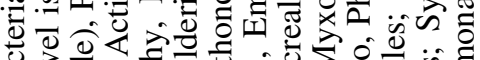

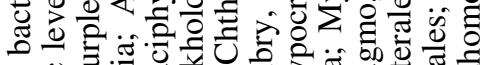

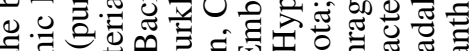
政

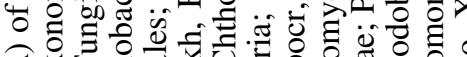

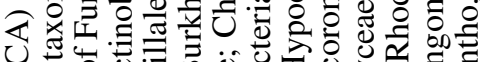
U U

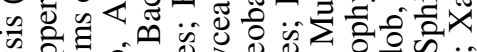

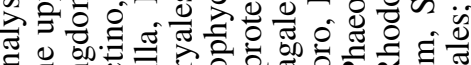

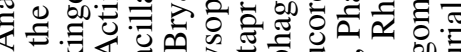
\& क 현

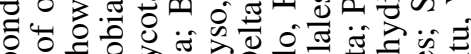

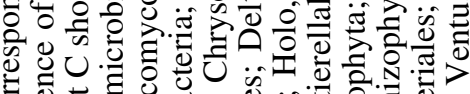
论

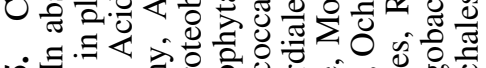

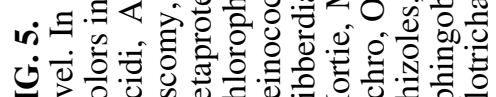

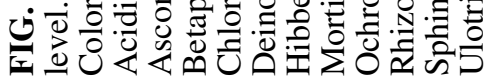


Table 1. Richness (Operational Taxonomic Units), SHANNON-Wiener $\left(\mathrm{H}^{\prime}\right)$ Diversity, Simpson Diversity, AND EVENNESS INDICES FROM THE HIGH-THROUGHPUT

Sequencing Data of the Bacterial and ArChaEal 16S RRNA GENES, AND THE EUKARYOTIC 18S RRNA GENE From the Three Microbial Mats

\begin{tabular}{lccc}
\hline & Mat-1 $\left(88^{\circ} \mathrm{C}\right)$ & Mat-2 $\left(8^{\circ} \mathrm{C}\right)$ & Mat-3 $\left(2^{\circ} \mathrm{C}\right)$ \\
\hline Bacteria & & & \\
OTUs & 845 & 1214 & 976 \\
$\mathrm{H}^{\prime}$ & 3.73 & 5.24 & 4.02 \\
Simpson & 0.87 & 0.99 & 0.93 \\
$\quad$ Evenness & 0.55 & 0.74 & 0.58 \\
Archaea & & & \\
OTUs & 45 & 41 & 7 \\
$\mathrm{H}^{\prime}$ & 0.84 & 1.02 & 0.36 \\
Simpson & 0.49 & 0.53 & 0.13 \\
Evenness & 0.22 & 0.28 & 0.18 \\
Eukarya & & & \\
OTUs & 430 & 508 & 480 \\
$\mathrm{H}^{\prime}$ & 2.02 & 2.76 & 3.30 \\
Simpson & 0.68 & 0.87 & 0.89 \\
Evenness & 0.33 & 0.44 & 0.53 \\
\hline
\end{tabular}

OTUs = operational taxonomic units.

Thermus and Firmicutes showed the highest relative intensity signals in Mat-1, also coincident with DNA results. Bacteroidetes and Nitrospirae were immunodetected in the three mats, and Actinobacteria was detected in Mat-3. The LDChip also revealed the presence of halophiles in Mat-1 and Mat-3, and methanogens in Mat-3. In addition, LDChip recognized markers from enzymes involved in specific metabolisms such as iron storage and $\mathrm{SO}_{4}{ }^{2-}$ reduction in Mat-1 and Mat-3, respectively, and protein transporters in both Mat-1 and Mat-2.

\section{Discussion}

\subsection{Community structure and metabolism in the microbial mats from the geothermal band of Cerro Caliente}

The three microbial mats located in the geothermal summit of Cerro Caliente showed differences in their bacterial, archaeal, and eukaryotic community structures below the phylum level. Given the proximity between the three sampling sites and thus their similar mineralogy and geochemistry, other factors, such as temperature, may play a key role on determining their community structures. The selective pressure of temperature on microbial growth has

Table 2. Bray-Curtis Dissimilarity IndeX From the High-Throughput SEQuencing Data OF THE BACTERIAL AND ARCHAEAL 16S RRNA Genes, AND THE EUKARYOTIC 18S RRNA GENE FROM THE THREE Microbial MatS

\begin{tabular}{lccc}
\hline & Mat-1-Mat-2 & Mat-1-Mat-3 & Mat-2-Mat-3 \\
\hline Bacteria & 0.84 & 0.94 & 0.90 \\
Archaea & 0.37 & 1.00 & 1.00 \\
Eukarya & 0.58 & 0.90 & 0.93 \\
\hline
\end{tabular}

The index ranges from 0 to 1 , being 0 when a pair of samples shares the same OTU composition, and 1 when a pair of samples does not share any OTU. been widely described (Nedwell, 1999; Stetter, 1999, and references herein), and may explain the presence of thermal niches (Clarke, 2017a) in this study. We hypothesize that, in Cerro Caliente, temperature acts as a selective factor that favors preferential growth of specific thermally adapted microbial groups. Indeed, the microbial composition of the hottest mat (i.e., Mat-1) was characterized by a higher proportion of the bacterial orders Kallotenuales, Bacillales, Thermales, and Chthonomonadales, which were previously described as heat tolerant or thermophiles (Llarch et al., 1997; Muñoz et al., 2011; Cole et al., 2013; Lee et al., 2014; Bendia et al., 2018a). Contrarily, the coldest mat (i.e., Mat3) was characterized by a relatively higher proportion of the bacterial orders Flavobacteriales and Cytophagales, and the fungal order Rhizophydiales, previously described as cold tolerant or psychrophiles (Koo et al., 2014; Králová, 2017; Rojas-Jimenez et al., 2017).

Despite the higher proportion of thermal specialists in Mat1 and Mat-3 than in Mat-2, the three microbial mats shared main phyla (e.g., Cyanobacteria, Proteobacteria, Bacteroidetes, and Deinococcus-Thermus) and a proportion of OTUs (15\% of bacteria, $6 \%$ of archaea, and $7 \%$ of eukaryotes). These similarities between mats despite their different temperatures recorded at the time of collection $\left(88^{\circ} \mathrm{C}, 8^{\circ} \mathrm{C}\right.$, and $2^{\circ} \mathrm{C}$ ) suggest that water movement along the ground transect and/or ground thermal oscillations may contribute to comparable community structures. Indeed, the daily thermal oscillations of the ground recorded over the year (Fig. 2) indicate that mat temperatures may have been fluctuating, possibly by a mobility of thermal fluids underneath Cerro Caliente and oscillations in the atmospheric temperature.

In a geothermal area, thermal conditions cannot be regarded as static values, but rather dynamic features that typically alternate between activity and inactivity in subsurface fracture systems (Fournier, 1989). Consequently, our study represents a snapshot in time, used to document and compare the microbial community of the three microbial mats at the time of collection but possibly integrating fingerprints from microorganisms that may have been active when the temperatures were within their optimal or tolerance limits for growth. The detection of $75 \%$ of green algae and $41 \%$ of Cyanobacteria in Mat-1 (i.e., $88^{\circ} \mathrm{C}$ at the time of collection) supports this hypothesis, since the thermal maximum limit for photosynthesis is $73^{\circ} \mathrm{C}$ (Brock, 1967; Castenholz, 1969). The grayish appearance of Mat-1 (Fig. 1) also supports the inactivity of chlorophyll-bearing microorganisms at the time of collection. Thus, it indicates the preservation of genomic material from photosynthetic microorganisms that were active when lower temperatures allowed photosynthesis to occur. Moreover, the presence of certain thermophiles and psychrophiles in the three mats also supports the influence of the ground thermal dynamics in the composition of the microbial mats. For instance, thermophiles from the order Ktedonobacterales (Yabe et al., 2017) were identified in Mat-2 $\left(8^{\circ} \mathrm{C}\right)$, and cold-tolerant lichen-associated fungi Hypocreales and Coniochaetales were present in Mat-1 $\left(88^{\circ} \mathrm{C}\right)$ (Park et al., 2015; Zhang et al., 2016). These findings agree with the uneven distribution of thermophiles and psychrophiles in cold and hot soils observed in other locations from Deception Island (Bendia et al., 2018a, 2018b) and suggest that microbial mats in Cerro Caliente can adapt to steep temperature gradients through a heterogeneous microbial composition with different 


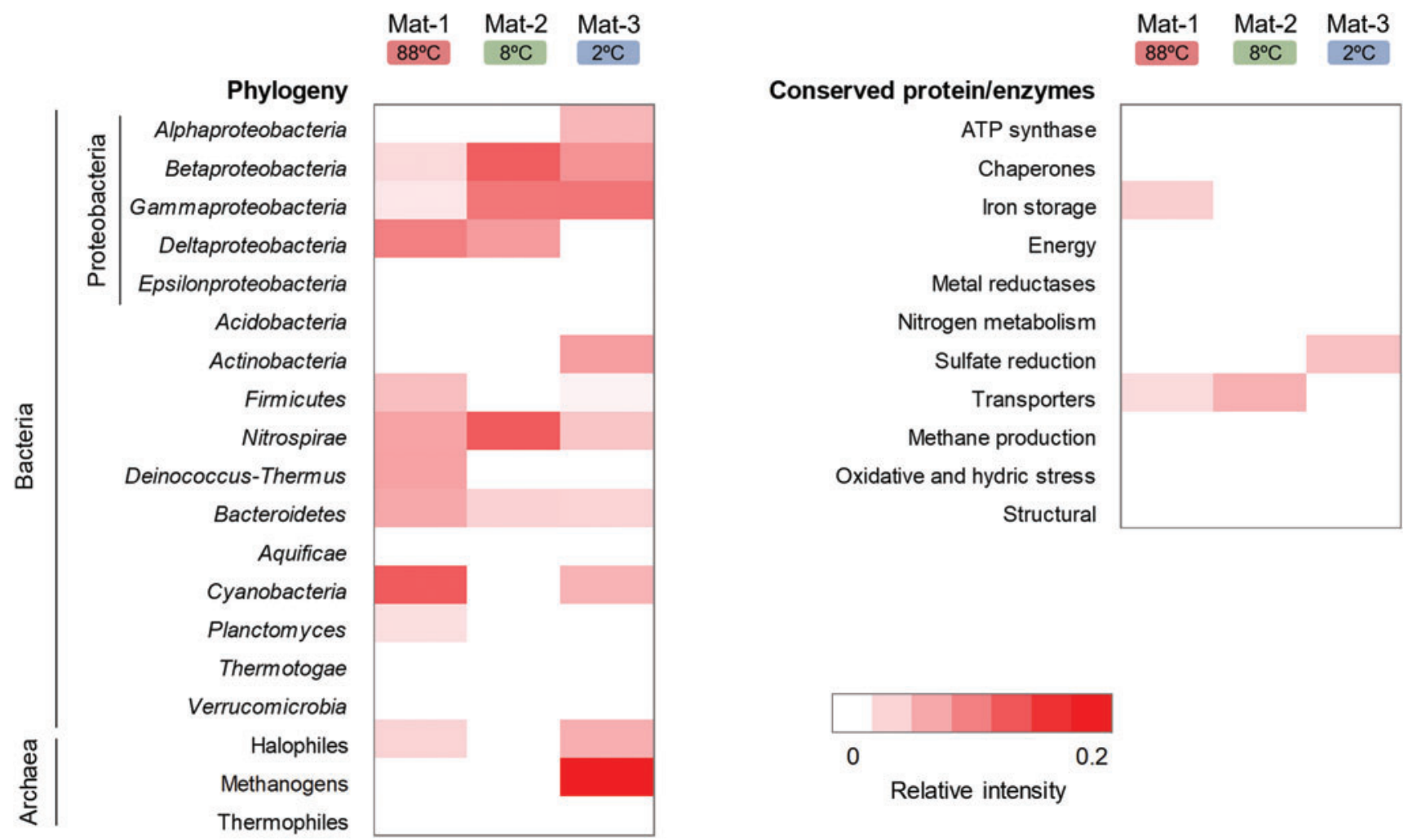

FIG. 6. Heatmap of the LDChip immunoassay analysis on the three microbial mats. The antibodies (Supplementary Table S1) were organized into 30 categories based on main phylogenetic groups, metabolic traits, and protein functions. Only phylum Proteobacteria is divided into five taxonomic classes. The averaged fluorescence intensity of the positive signals within each category was used for relative intensity calculation. The color scale represents the relative intensity of the positive signals. White cells stand for values under the detection limit and positive signals are indicated from light pink to red (0.2 as maximum relative intensity). LDChip, Life Detector Chip.

thermal traits. Although geochemical variations at a small spatial scale and their possible influence on the community composition cannot be discarded either (Bendia et al., 2018b), temperature appears to be a more determinant factor modeling the microbial communities in hot springs and other geothermal environments (Wang et al., 2013; Sharp et al., 2014).

The diversity and richness of the microbial mat communities appeared to be also influenced by temperature. The lower diversity and richness values in Mat-1 (i.e., $88^{\circ} \mathrm{C}$ at the time of collection) as compared with the other two mats $\left(8^{\circ} \mathrm{C}\right.$ and $\left.2^{\circ} \mathrm{C}\right)$ were interpreted as a result of the microbial adaptation to high temperatures and the selection and development of high-temperature specialists in the microbial mat. The influence of temperature on the microbial richness and diversity in geothermal environments was deeply studied in Sharp et al. (2014) and concluded that extreme temperatures cause stress and selection of few adapted individuals, thus exerting a strong control on microbial diversity and richness. The low archaeal diversity in the mats from Cerro Caliente as compared with samples from other locations in Deception Island (Signori et al., 2014; Bendia et al., 2018b) may be explained either by the low archaeal evenness or by a dominance of bacteria and eukaryotes in the geothermal band of Cerro Caliente.

The larger TOC and TN values observed in the mat at $88^{\circ} \mathrm{C}$ (i.e., Mat-1) suggest the influence of temperature on the stimulation of the microbial growth, as temperature is known to increase physiological processes (Clarke, 2017b). The bulk carbon and nitrogen isotopic composition of the microbial mats also evidenced different metabolic traits as a function of temperature. For instance, the relatively enriched $\delta^{13} \mathrm{C}$ ratio observed in Mat-1 suggests $\mathrm{CO}_{2}$ fixation pathways mostly related to the reductive tricarboxylic acid (rTCA) cycle (Preuß et al., 1989) and/or the 3hydroxypropionate (3HP) bicycle (Van Der Meer et al., 2001). This is consistent with the detection of Chloroflexi, Armatimonadetes, Nitrospirae, and Aquificae (this one at relative abundance $<0.5 \%$ ) (Herter et al., 2002; Hügler et al., 2007; Hügler and Sievert, 2011; Lee et al., 2014; AlcamánArias et al., 2018). The dominance of rTCA or $3 \mathrm{HP}$ processes also suggests the lower oxygen availability prevailing under the surface of Mat-1, which is consistent with the generally more oxygen depletion in high-temperature habitats (Hügler and Sievert, 2011) and the presence of facultative/strict anaerobes, such as Gemmatimonadales (e.g., Gemmatimonas) and Holophagales (e.g., Geothrix) (Coates et al., 1999; Zhang et al., 2003). In contrast, the relatively depleted $\delta^{13} \mathrm{C}$ isotopic ratios in Mat-2 and Mat-3 revealed a larger implication of the Calvin-Benson-Bassham (CBB) cycle for $\mathrm{CO}_{2}$ fixation. This agreed with the presence of bryophytes, green algae, and cyanobacteria in both mats, was coherent with the greener appearance of Mat-2 (Fig. 1), and was congruent with the temperatures measured in both mats at the time of collection $\left(8^{\circ} \mathrm{C}\right.$ and $\left.2^{\circ} \mathrm{C}\right)$, which are compatible with photosynthesis. 
Regarding the nitrogen isotopic composition, the wide range of $\delta^{15} \mathrm{~N}$ found within the microbial mats (Fig. 3D) reflected distinct participations in the nitrogen cycle. The most enriched $\delta^{15} \mathrm{~N}$ ratio in Mat-3 revealed the possible contribution of photosynthetically active cyanobacteria (e.g., order Nostocales) and other microorganisms in nitrogen fixation (Rowell et al., 1998). In contrast, the very $\delta^{15} \mathrm{~N}$ depleted signature of Mat-1 and Mat-2 suggests a deep and continuous processing of the organic matter within the nitrogen cycle. Wet and cold ecosystems are known to have $\delta^{15} \mathrm{~N}$-depleted organic values relative to atmospheric $\mathrm{N}_{2}$ (e.g., Handley et al., 1999, and references therein). Although the origin of the depleted values is unclear, Handley et al. (1999) argued that depleted $\delta^{15} \mathrm{~N}$ values could reflect the interaction of internal cycling of nitrogen between live (e.g., active microbial metabolism) and dead organic pools.

According to the microbial composition of the mats, main survival strategies in Cerro Caliente seem to be related to maintain cells active under peaks of extreme high and low temperatures, by combining physiological features and nutritional requirements. Specific lipid membrane composition for thermal stability and ultraviolet resistance (e.g., Thermales, Yang et al., 2006), chemolitothrophy (e.g., ammonia oxidation in Nitrososphaerales, Stieglmeier et al., 2014), and partition of carbon fixation pathways under high temperatures (e.g., rTCA in Nitrospirae, Hügler and Sievert, 2011) are likely the most relevant survival strategies in the mats. The unexpected low relative abundance of the phylum Firmicutes may indicate that spore formation represent a low relevant strategy in the geothermal site of Cerro Caliente. In fact, the annual mean temperature was $27^{\circ} \mathrm{C}$, which is optimal for the growth of a wide range of microbial phyla. The absence of the phylum Firmicutes on the surface of permafrost in Deception Island (Blanco et al., 2012), and on the surface of sediments from fumarole and glacier sites (Bendia et al., 2018b), also supports this hypothesis, since surface cooling or warming may buffer extreme temperatures and cause milder thermal conditions. This is also consistent with the detection of the phylum Firmicutes in deeper samples of permafrost $(0.6-4.5 \mathrm{~m})$ in Deception Island (Blanco et al., 2012) and those at $\sim 10 \mathrm{~m}$ depth in Alaska permafrost (MacKelprang et al., 2017), where low temperatures were stable over time.

\subsection{Search for microbial markers with LDChip multiplex immunoassay}

Similarities observed between the LDChip and the DNA analyses in the composition of the major bacterial phyla (e.g., Cyanobacteria, Proteobacteria, and DeinococcusThermus) highlight the utility of the LDChip for microbial marker detection and determination of the bulk microbial composition of heterogeneous environmental samples. The relationship between immunodetection of methanogens in Mat-3 and the $96 \%$ Euryarchaeota with DNA analyses (Nichols et al., 2004; Berg et al., 2010) also supports the use of LDChip to get insight into microbial metabolic processes. The detection of methanogens and sulfur reducers in Cerro Caliente is also consistent with the presence of methanogens and sulfur reducers in permafrost and soil samples in other locations of Deception Island (Blanco et al., 2012; Bendia et al., 2018b).
The LDChip is an antibody microarray immunosensor and the core sensing element of Signs Of Life Detector (SOLID), an instrument designed for in situ analysis of soil or powdered samples to detect biological polymers and small molecules with interest for planetary exploration (Parro et al., 2005, 2011; Rivas et al., 2008; Blanco et al., 2018; Moreno-Paz et al., 2018). The observed capacity of the LDChip for the detection of molecular markers of the major bacterial phyla in the microbial mats supports SOLID instrument in forthcoming planetary missions such as IceBreaker, aiming to search for biochemical evidence of life in the martian permafrost (McKay et al., 2013; McKay and Parro, 2014). At present, few limitations exist for a thorough analysis of the microbial mat composition with LDChip, including identification of the minor bacterial phyla. Currently, LDChip is under a continuous improvement process by increasing the number of antibodies per phyla and an enhancement of the signal sensitivity to benefit the LDChip performance.

\subsection{Cerro Caliente as an astrobiological analog for early Mars}

Geothermal environments in polar volcanoes constitute a proxy to glimpse into potentially habitable environments beyond Earth, such as Mars and other planetary bodies (Schmidt et al., 2011; Hsu et al., 2015). Our investigations in Cerro Caliente outlined here can serve as an analog of early Mars, when conditions were warmer and wetter than today (Squyres and Kasting, 1994). For instance, the cratered Noachian-aged terrains of Mars are deeply dissected by multiple systems of fluvial valley networks and crater and intercrater lakes (Gulick and Baker, 1989), interpreted as a result from a period of rainfall and surface runoff on early Mars (Craddock and Howard, 2002; Ramirez and Craddock, 2018). This presence of liquid water on the surface, however, is difficult to reconcile with the reduced solar luminosity ca. $3.8 \mathrm{Ga}$. ago and before (the Sun was $\sim 25 \%$ fainter than today, Spalding et al., 2018). These conditions would have imposed mean temperatures below freezing all over the planet and a climate dominated by generally cold conditions (Fairén et al., 2012). A plausible explanation for flowing liquid water on early Mars is the persistence of glaciovolcanic processes, in which the interaction of volcanic and magmatic activity with surface and subsurface water ice deposits provided liquid water (Smellie and Chapman, 2002; Wilson and Head, 2007; Edwards et al., 2014).

Previous investigations have identified glaciovolcanic features at local scales on Mars, for example, on the flanks of Arsia Mons (Scanlon et al., 2014, 2015), and have been pointed as the origin of local fluvial features. Consequently, it has been suggested that early Mars was affected by the triple point of water during geologically important periods of time, when widespread extensions of soft and deformable ice coexisted with large amounts of water vapor and scarce liquid water. Therefore, glaciomagmatic interactions may have played an important role in volcanic flanks, triggering an active water cycle that altered the landscape and affected the stratigraphy, rock composition, and weathering (Fairén, 2010, 2017).

The evidence of past glaciovolcanic activity promoting fluvial processes on early Mars also allows to hypothesize 
that Mars had favorable conditions (e.g., liquid water, sources of energy, and nutrients) to trigger processes similar to those that led to the origin of life in our planet (McKay and Stoker, 1989). The polar volcanic environment of Cerro Caliente thus serves as an analog for potential habitable sites on early Mars that could have provided refugia for any developing life (with the common caveats shared by all terrestrial analogs, such as the oxygen availability). The coexistence of evolutionarily distant microorganisms (from Thaumarchaeota to Chlorophyta) with different thermal tolerances (some adapted to extreme high and cold temperatures) and metabolisms (partition of different $\mathrm{CO}_{2}$ fixation pathways) in Cerro Caliente provides diverse molecular biomarker signatures useful to interpret extant or extinct life in current (Mars Science Laboratory) or future (ExoMars and Mars 2020) planetary missions to Mars.

\section{Conclusions}

Microbial mats from Cerro Caliente were assessed with a multianalytical approach to characterize their composition and major metabolisms under variable thermal conditions. The analysis of SSU rRNA genes, multiplex immunoassays, and stable isotope composition evidenced microbial mat composition with different thermal tolerances and metabolisms as a function of the prevailing temperature of each mat. The mat at $88^{\circ} \mathrm{C}$ showed higher proportion of thermophiles and the rTCA or 3HP cycles as the major carbon fixation pathways, and the mats at $8^{\circ} \mathrm{C}$ and $2^{\circ} \mathrm{C}$ showed higher proportion of psychrophiles and the CBB cycle. Beyond this thermal pattern, the three mats shared main microbial phyla, most likely explained by the strong thermal oscillations recorded in the ground over the year. Therefore, thermal factors must be considered to explain the overall microbial community structure and operating metabolisms in Cerro Caliente.

The interest of glaciovolcanic environments as potential habitable sites on early Mars highlights Cerro Caliente as a relevant analog for the study of molecular microbial markers. The correlation between genetic analyses and immunoassays supports the use of the LDChip as a powerful tool for a comprehensive microbial study and its suitability for searching signs of life beyond Earth. Finally, our work stresses on the particularity of Cerro Caliente as a unique habitat with a remarkable environmental value for ecological studies and reinforces its special protection status as ASPA 140.

\section{Acknowledgments}

We thank María Teresa Fernández Sampedro for technical assistance in X-ray diffraction analysis. We also thank the personnel of the Spanish Antarctic Base "Gabriel de Castilla," headed by Commandant Antonio Casals Abraham, for their assistance in field and logistics. This study has been funded by the Spanish Research Agency (AEI) from the Ministry of Science Innovation and Universities and the European FEDER Grants Nos. ESP2015-69540-R, RYC2014-19446, and CGL2015-74254-JIN; the AEI Project No. MDM-2017-0737 Unidad de Excelencia "María de Maeztu," and the European Research Council Starting Grant (ERC StG) No. 307496. M.Á. Lezcano and M.Á. FernándezMartínez were supported by a postdoctoral fellowship by the
Youth Employment Initiative from the European Union and implanted in Comunidad de Madrid. We recognize the work of the two anonymous reviewers to improve the article.

\section{Author Disclosure Statement}

No competing financial interest exist.

\section{Supplementary Material}

Supplementary Table S1

\section{References}

Alcamán-Arias, M.E., Pedrós-Alió, C., Tamames, J., Fernández, C., Pérez-Pantoja, D., Vásquez, M., and Díez, B. (2018) Diurnal changes in active carbon and nitrogen pathways along the temperature gradient in Porcelana hot spring microbial mat. Front Microbiol 9:2353.

Amenábar, M.J., Flores, P.A., Pugin, B., Boehmwald, F.A., and Blamey, J.M. (2013) Archaeal diversity from hydrothermal systems of Deception Island, Antarctica. Polar Biol 36:373-380.

ATS (Antarctic Treaty Secretariat). (2012) Management plan for Antarctic Specially Managed Area No. 140. Parts of Deception Island, South Shetland Islands. In ATCM XXXV Final Report. Secretariat of the Antarctic Treaty. Hobart, Australia, pp 99-124.

Baker, P.E. and McReath, I. (1971) 1970 Volcanic eruption at Deception Island. Nat Phys Sci 231:5-9.

Barnes, D.K.A., Linse, K., Enderlein, P., Smale, D., Fraser, K.P.P., and Brown, M. (2008) Marine richness and gradients at Deception Island, Antarctica. Antarct Sci 20:271-279.

Bendia, A.G., Araujo, G.G., Pulschen, A.A., Contro, B., Duarte, R.T.D., Rodrigues, F., Galante, D., and Pellizari, V.H. (2018a) Surviving in hot and cold: psychrophiles and thermophiles from Deception Island volcano, Antarctica. Extremophiles 22:917-929.

Bendia, A.G., Signori, C.N., Franco, D.C., Duarte, R.T.D., Bohannan, B.J.M., and Pellizari, V.H. (2018b) A mosaic of geothermal and marine features shapes microbial community structure on deception Island Volcano, Antarctica. Front Microbiol 9:1-13.

Berg, I.A., Kockelkorn, D., Ramos-Vera, W.H., Say, R.F., Zarzycki, J., Hügler, M., Alber, B.E., and Fuchs, G. (2010) Autotrophic carbon fixation in archaea. Nat Rev Microbiol 8:447-460.

Blanco, Y., Prieto-Ballesteros, O., Gómez, M.J., Moreno-Paz, M., García-Villadangos, M., Rodríguez-Manfredi, J.A., CruzGil, P., Sánchez-Román, M., Rivas, L.A., and Parro, V. (2012) Prokaryotic communities and operating metabolisms in the surface and the permafrost of Deception Island (Antarctica). Environ Microbiol 14:2495-2510.

Blanco, Y., Moreno-Paz, M., and Parro, V. (2017) Experimental protocol for detecting cyanobacteria in liquid and solid samples with an antibody microarray chip. J Vis Exp 120:e54994.

Blanco, Y., de Diego-Castilla, G., Viúdez-Moreiras, D., Cavalcante-Silva, E., Rodríguez-Manfredi, J.A., Davila, A.F., McKay, C.P., and Parro, V. (2018) Effects of gamma and electron radiations on the structural integrity of organic molecules and macromolecular biomarkers measured by microarray immunoassays and their astrobiological implications. Astrobiology 18:ast.2016.1645.

Brock, T.D. (1967) Microorganisms adapted to high temperatures. Nature 214:597-598.

Cameron, R.J. and Benoit, R.E. (1970) Microbial and ecological investigations of recent cinder cones, Deception Island, Antarctica-A preliminary report. Ecology 51:802-809. 
Carrión, O., Miñana-Galbis, D., Montes, M.J., and Mercadé, E. (2011) Pseudomonas deceptionensis sp. nov., a psychrotolerant bacterium from the Antarctic. Int J Syst Evol Microbiol 61:2401-2405.

Caselli, A.T., Santos Afonso, M.dos, and Agusto, M.R. (2004) The fumarolic gases at Deception Island (South Shetland Islands, Antarctica): chemical changes and deposits related to seismic crisis of 1999. Revista de la Asociacion Geológica Argentina 59:291-302.

Caselli, A.T., Badi, G., Bonatto, A.L., Bengoa, C.L., Agusto, M.R., Bidone, A., and Ibáñez, J. (2007) Seismic activity and an anomalous fumarolic chemical composition due to seal effect in the volcanic system of Deception Island (Antarctica). Revista de la Asociación Geológica Argentina 62:545-552.

Castenholz, R.W. (1969) Thermophilic blue-green algae and the thermal environment. Bacteriol Rev 33:476-504.

Chao, A., Ma, K.H., and Hsieh, T.C. (2016) iNEXT (iNterpolation and EXTrapolation). Online: Software for Interpolation and Extrapolation of Species Diversity.

Clarke, A. (2017a) Global climate change and its ecological consequences. In Principles of Thermal Ecology: Temperature, Energy, and Life, edited by A. Clarke, Oxford University Press, Oxford, pp 354-390.

Clarke, A. (2017b) Temperature and reaction rate. In Principles of Thermal Ecology: Temperature, Energy, and Life, edited by A. Clarke. Oxford University Press, Oxford, pp 131-162.

Coates, J.D., Ellis, D.J., Gaw, C.V., and Lovley, D.R. (1999) Geothrix ferrnentans gen. nov., sp. nov., a novel Fe(III)reducing bacterium from a hydrocarbon-contaminated aquifer. Int J Syst Bacteriol 49:1615-1622.

Cole, J.K., Gieler, B.A., Heisler, D.L., Palisoc, M.M., Williams, A.J., Dohnalkova, A.C., Ming, H., Yu, T.T., Dodsworth, J.A., Li, W.-J., and Hedlund, B.P. (2013) Kallotenue papyrolyticum gen. nov., sp. nov., a cellulolytic and filamentous thermophile that represents a novel lineage (Kallotenuales ord. nov., Kallotenuaceae fam. nov.) within the class Chloroflexia. Int J Syst Evol Microbiol 63:4675-4682.

Cole, J.R., Wang, Q., Fish, J.A., Chai, B., McGarrell, D.M., Sun, Y., Brown, C.T., Porras-Alfaro, A., Kuske, C.R., and Tiedje, J.M. (2014) Ribosomal Database Project: data and tools for high throughput rRNA analysis. Nucleic Acids Res 42:633-642.

Craddock, R.A. and Howard, A.D. (2002) The case for rainfall on a warm, wet early Mars. J Geophys Res Planets 107:21-121-36.

Cruaud, P., Vigneron, A., Lucchetti-Miganeh, C., Ciron, P.E., Godfroy, A., Cambon-and Bonavita, M.A. (2014) Influence of DNA extraction method, 16S rRNA targeted hypervariable regions, and sample origin on microbial diversity detected by 454 pyrosequencing in marine chemosynthetic ecosystems. Appl Environ Microbiol 80:4626-4639.

Deamer, D.W. and Georgiou, C.D. (2015) Hydrothermal conditions and the origin of cellular life. Astrobiology 15:1091-1095.

Dutta, A. and Chaudhuri, K. (2010) Analysis of tRNA composition and folding in psychrophilic, mesophilic and thermophilic genomes: indications for thermal adaptation. FEMS Microbiol Lett 305:100-108.

Edwards, B.R., Belousov, A., and Belousova, M. (2014) Propagation style controls lava-snow interactions. Nat Commun 5:1-5.

Fairén, A.G. (2010) A cold and wet Mars. Icarus 208:165-175.

Fairén, A.G. (2017) Icy Mars lakes warmed by methane. Nat Geosci 10:717-718.

Fairén, A.G., Haqq-Misra, J.D., and McKay, C.P. (2012) Reduced albedo on early Mars does not solve the climate paradox under a faint young Sun. $A \& A$ 540:A13.
Fermani, P., Mataloni, G., and Van De Vijver, B. (2007) Soil microalgal communities on an antarctic active volcano (Deception Island, South Shetlands). Polar Biol 30:1381-1393.

Flores, P.A.M., Correa-Llantén, D.N., and Blamey, J.M. (2018) A thermophilic microorganism from Deception Island, Antarctica with a thermostable glutamate dehydrogenase activity. Biol Res 51:55.

Fournier, R.O. (1989) Geochemistry and dynamics of the Yellowstone National Park Hydrothermal System. Annu Rev Earth Planet Sci 177:13-53.

Fraser, C.I., Terauds, A., Smellie, J., Convey, P., and Chown, S.L. (2014) Geothermal activity helps life survive glacial cycles. Proc Natl Acad Sci U S A 111:5634-5639.

Gulick, V. and Baker, V.R. (1989) Fluvial valleys and martian palaeoclimates. Nature 341:514-516.

Handley, L.L., Austin, A.T., Robinson, D., Scrimgeour, C.M., Raven, J.A., Heaton, T.H.E., Schmidt, S., and Stewart, G.R. (1999) The $15 \mathrm{~N}$ natural abundance $\left(\delta^{15} \mathrm{~N}\right)$ of ecosystem samples reflects measures of water availability. Aust J Plant Physiol 26:185-199.

He, Z., Gentry, T.J., Schadt, C.W., Wu, L., Liebich, J., Chong, S.C., Huang, Z., Wu, W., Gu, B., Jardine, P., Criddle, C., and Zhou, J. (2007) GeoChip: a comprehensive microarray for investigating biogeochemical, ecological and environmental processes. ISME J 1:67-77.

Herbold, C.W., McDonald, I.R., and Cary, S.C. (2014) Microbial ecology of geothermal habitats in Antarctica. In Antarctic Terrestrial Microbiology, edited by D.A. Cowan, SpringerVerlag, Berlin Heidelberg, pp 181-215.

Herlemann, D.P.R., Labrenz, M., Jürgens, K., Bertilsson, S., Waniek, J.J., and Andersson, A.F. (2011) Transitions in bacterial communities along the $2000 \mathrm{~km}$ salinity gradient of the Baltic Sea. ISME J 5:1571-1579.

Herter, S., Fuchs, G., Bacher, A., and Eisenreich, W. (2002) A bicyclic autotrophic $\mathrm{CO}_{2}$ fixation pathway in Chloroflexus aurantiacus. J Biol Chem 277:20277-20283.

Hsu, H.W., Postberg, F., Sekine, Y., Shibuya, T., Kempf, S., Horányi, M., Juhász, A., Altobelli, N., Suzuki, K., Masaki, Y., Kuwatani, T., Tachibana, S., Sirono, S.I., MoragasKlostermeyer, G., and Srama, R. (2015) Ongoing hydrothermal activities within Enceladus. Nature 519:207-210.

Hugerth, L.W., Muller, E.E.L., Hu, Y.O.O., Lebrun, L.A.M., Roume, H., Lundin, D., Wilmes, P., and Andersson, A.F. (2014) Systematic design of $18 \mathrm{~S}$ rRNA gene primers for determining eukaryotic diversity in microbial consortia. PLoS One 9:e95567.

Hügler, M. and Sievert, S.M. (2011) Beyond the Calvin cycle: autotrophic carbon fixation in the ocean. Annu Rev Marine Sci 3:261-289.

Hügler, M., Huber, H., Molyneaux, S.J., Vetriani, C., and Sievert, S.M. (2007) Autotrophic $\mathrm{CO}_{2}$ fixation via the reductive tricarboxylic acid cycle in different lineages within the phylum Aquificae: evidence for two ways of citrate cleavage. Environ Microbiol 9:81-92.

Koo, H., Ptacek, T., Crowley, M., Swain, A.K., Osborne, J.D., Bej, A.K., and Andersen, D.T. (2014) Draft genome sequence of Hymenobacter sp. strain IS2118, isolated from a freshwater lake in Schirmacher Oasis, Antarctica, reveals diverse genes for adaptation to cold ecosystems. Genome Announc 2: e00739-14.

Kozich, J.J., Westcott, S.L., Baxter, N.T., Highlander, S.K., and Schloss, P.D. (2013) Development of a dual-index sequencing strategy and curation pipeline for analyzing amplicon sequence data on the MiSeq Illumina sequencing platform. Appl Environ Microbiol 79:5112-5120. 
Králová, S. (2017) Role of fatty acids in cold adaptation of Antarctic psychrophilic Flavobacterium spp. Syst Appl Microbiol 40:329-333.

Lee, K.C., Morgan, X.C., Dunfield, P.F., Tamas, I., Mcdonald, I.R., and Stott, M.B. (2014) Genomic analysis of Chthonomonas calidirosea, the first sequenced isolate of the phylum Armatimonadetes. ISME J 8:1522-1533.

Llarch, À., Logan, N., Castellvi, J., Prieto, M., and Guinea, J. (1997) Isolation and characterization of thermophilic Bacillus spp. from geothermal environments on Deception Island, South Shetland Archipelago. Microb Ecol 34:58-65.

Logan, N.A. and Allan, R.N. (2008) Aerobic, endospore-forming bacteria from Antarctic geothermal soils. In Microbiology of Extreme Soils. Soil Biology, edited by P. Dion, C.S. Nautiyal. Springer Verlag, Berlin, Heidelberg, pp 155-175.

MacKelprang, R., Burkert, A., Haw, M., Mahendrarajah, T., Conaway, C.H., Douglas, T.A., and Waldrop, M.P. (2017) Microbial survival strategies in ancient permafrost: insights from metagenomics. ISME $J$ 11:2305-2318.

Matsuoka, K., Skoglund, A., and Roth, G. (2018) Quantartica [Data Set]. Norwegian Polar Institute. Available online at https://data.npolar.no/dataset/8516e961-81db-4120-af13-b8a $2 \mathrm{ffe} 174 \mathrm{c} 9$

McKay, C.P., and Parro, V. (2014) How to search for life on Mars. Sci Am 310:46-49.

McKay, C.P., and Stoker, C.R. (1989) The early environment and its evolution on Mars: implications for life. Rev Geophys 27:189-214.

McKay, C.P., Stoker, C.R., Glass, B.J., Davé AI, Davila, A.F., Heldmann, J.L., Marinova, M.M., Fairen, A.G., Quinn, R.C., Zacny, K.A., Paulsen, G., Smith, P.H., Parro, V., Andersen, D.T., Hecht, M.H., Lacelle, D., and Pollard, W.H. (2013) The Icebreaker Life Mission to Mars: a search for biomolecular evidence for life. Astrobiology 13:334-353.

Miller, S.R., Strong, A.L., Jones, K.L., and Ungerer, M.C. (2009) Bar-coded pyrosequencing reveals shared bacterial community properties along the temperature gradients of two alkaline hot springs in Yellowstone National Park. Appl Environ Microbiol 75:4565-4572.

Moreno-Paz, M., Gómez-Cifuentes, A., Ruiz-Bermejo, M., Hofstetter, O., Maquieira, Á., Manchado, J.M., Morais, S., Sephton, M.A., Niessner, R., Knopp, D., and Parro, V. (2018) Detecting nonvolatile life- and nonlife-derived organics in a carbonaceous chondrite analogue with a new multiplex immunoassay and its relevance for planetary exploration. Astrobiology 18:1041-1056.

Mulkidjanian, A.Y., Bychkov, A.Y., Dibrova, D.V., Galperin, M.Y., and Koonin, E.V. (2012) Origin of first cells at terrestrial, anoxic geothermal fields. Proc Natl Acad Sci USA 109:E821-E830.

Muñoz, P.A., Flores, P.A., Boehmwald, F.A., and Blamey, J.M. (2011) Thermophilic bacteria present in a sample from Fumarole Bay, Deception Island. Antarct Sci 23:549-555.

Nedwell, D.B. (1999) Effect of low temperature on microbial growth: lowered affinity for substrates limits growth at low temperature. FEMS Microbiol Ecol 30:101-111.

Nichols, D.S., Miller, M.R., Davies, N.W., Goodchild, A., Raftery, M., and Cavicchioli, R. (2004) Cold adaptation in the Antarctic archaeon Methanococcoides burtonii involves membrane lipid unsaturation. J Bacteriol 186:8508-8515.

Oksanen, J., Blanchet, F.G., Friendly, M., Kindt, R., Legendre, P., McGlinn, D., Minchin, P.R., O’Hara, R.B., Simpson, G.L., Solymos, P., Stevens, H., Szoecs, E., and Wagner, H. (2017) Vegan: community ecology package. Ordination methods, diversity analysis and other functions for community and vegetation ecologists. Version 2.4-4.

Park, C.H., Kim, K.M., Elvebakk, A., Kim, O.-S., Jeong, G., and Hong, S.G. (2015) Algal and fungal diversity in Antarctic Lichens. J Eukaryot Microbiol 62:196-205.

Parro, V., Rodríguez-Manfredi, J.A., Briones, C., Compostizo, C., Herrero, P.L., Vez, E., Sebastián E, Moreno-Paz, M., García-Villadangos, M., Fernández-Calvo, P., GonzálezToril, E., Pérez-Mercader, J., Fernández-Remolar, D., and Gómez-Elvira, J. (2005) Instrument development to search for biomarkers on Mars: terrestrial acidophile, iron-powered chemolithoautotrophic communities as model systems. Planet Space Sci 53:729-737.

Parro, V., Fernández-Calvo, P., Rodríguez Manfredi, J.A., Moreno-Paz, M., Rivas, L.A., García-Villadangos, M., Bonaccorsi, R., González-Pastor, J.E., Prieto-Ballesteros, O., Schuerger, A.C., Davidson, M., Gómez-Elvira, J., and Stoker, C.R. (2008) SOLID2: an antibody array-based life-detector instrument in a Mars Drilling Simulation Experiment (MARTE). Astrobiology 8:987-999.

Parro, V., Diego-Castilla G de, Rodríguez-Manfredi, J.A., Rivas, L.A., Blanco-López, Y., Sebastián, E., Romeral, J., Compostizo, C., Herrero, P.L., García-Marín, A., MorenoPaz, M., García-Villadangos, M., Cruz-Gil, P., Peinado, V., Martín-Soler, J., Pérez-Mercader, J., and Gómez-Elvira, J. (2011) SOLID3: a multiplex antibody microarray-based optical sensor instrument for in situ life detection in planetary exploration. Astrobiology 11:15-28.

Preuß, A., Schauder, R., Fuchs, G., and Stichler, W. (1989) Carbon isotope fractionation by autotrophic bacteria with three different $\mathrm{CO}_{2}$ fixation pathways. Z Naturforsch C J Biosci 44:397-402.

Ramirez, R.M. and Craddock, R.A. (2018) The geological and climatological case for a warmer and wetter early Mars. Nat Geosci 11:230-237.

Reed, C.J., Lewis, H., Trejo, E., Winston, V., and Evilia, C. (2013) Protein adaptations in archaeal extremophiles. Archaea 2013:1-14.

Révész, K., Qi, H., and Coplen, T.B. (2012) Determination of the $\delta^{15} N$ and $\delta^{13} C$ of Total Nitrogen and Carbon in Solids, RSIL Lab Code 1832. Chapter 5. Methods of the Reston Stable Isotope Laboratory (Slightly Revised from Version 1.1 Released in 2007). U.S. Geological Survey Techniques and Methods. Denver, CO.

Rey, J., Somoza, L., and Martínez-Frías, J. (1995) Tectonic, volcanic, and hydrothermal event sequence on Deception Island (Antarctica). Geomarine Lett 15:1-8.

Rivas, L.A., García-Villadangos, M., Moreno-Paz, M., CruzGil, P., Gómez-Elvira, J., and Parro, V. (2008) A 200antibody microarray biochip for environmental monitoring: searching for universal microbial biomarkers through immunoprofiling. Anal Chem 80:7970-7979.

Rivas, L.A., Aguirre, J., Blanco, Y., González-Toril, E., and Parro, V. (2011) Graph-based deconvolution analysis of multiplex sandwich microarray immunoassays: applications for environmental monitoring. Environ Microbiol 13:1421-1432.

Rojas-Jimenez, K., Wurzbacher, C., Bourne, E.C., Chiuchiolo, A., Priscu, J.C., and Grossart, H.-P. (2017) Early diverging lineages within Cryptomycota and Chytridiomycota dominate the fungal communities in ice-covered lakes of the McMurdo Dry Valleys, Antarctica. Sci Rep 7:15348.

Rowell, P., James, W., Smith, W.L., Handley, L.L., and Scrimgeour, C.M. (1998) $15 \mathrm{~N}$ discrimination in molybdenum- and vanadium-growth N2-fixing Anabaena variabilis and Azotobacter vinelandii. Soil Biol Biochem 30:21772180 . 
Russell, M. (2018) Green rust: the simple organizing "seed" of all life? Life 8:35.

Sánchez-García, L., Aeppli, C., Parro, V., Fernández-Remolar, D., García-Villadangos, M., Chong-Diaz, G., Blanco, Y., and Carrizo, D. (2018) Molecular biomarkers in the subsurface of the Salar Grande (Atacama, Chile) evaporitic deposits. Biogeochemistry 140:31-52.

Scanlon, K.E., Head, J.W., Wilson, L., and Marchant, D.R. (2014) Volcano-ice interactions in the Arsia Mons tropical mountain glacier deposits. Icarus 237:315-339.

Scanlon, K.E., Head, J.W., and Marchant, D.R. (2015) Volcanism-induced, local wet-based glacial conditions recorded in the Late Amazonian Arsia Mons tropical mountain glacier deposits. Icarus 250:18-31.

Schloss, P.D., Westcott, S.L., Ryabin, T., Hall, J.R., Hartmann, M., Hollister, E.B., Lesniewski, R.A., Oakley, B.B., Parks, D.H., Robinson, C.J., Sahl, J.W., Stres, B., Thallinger, G.G., Van Horn, D.J., and Weber, C.F. (2009) Introducing mothur: open-source, platform-independent, community-supported software for describing and comparing microbial communities. Appl Environ Microbiol 75:7537-7541.

Schmidt, B.E., Blankenship, D.D., Patterson, G.W., and Schenk, P.M. (2011) Active formation of "chaos terrain" over shallow subsurface water on Europa. Nature 479:502-505.

Sharp, C.E., Brady, A.L., Sharp, G.H., Grasby, S.E., Stott, M.B., and Dunfield, P.F. (2014) Humboldt's spa: microbial diversity is controlled by temperature in geothermal environments. ISME J 8:1166-1174.

Signori, C.N., Thomas, F., Enrich-Prast, A., Pollery, R.C.G., and Sievert, S.M. (2014) Microbial diversity and community structure across environmental gradients in Bransfield Strait, Western Antarctic Peninsula. Front Microbiol 5:1-12.

Smellie, J.C. and López-Martínez, J. (2002) Introduction. In Geology and Geomorphology of Deception Island, edited by J. López-Martínez, J.L. Smellie, J.W. Thomson, M.R.A. Thomson, British Antarctic Survey. Natural Environment Research Council, Cambridge, pp 1-6.

Smellie, J.L. and Chapman, M.G. (2002) Volcano-Ice Interaction on Earth and Mars. Special Publications. Geological Society of London, London.

Somoza, L., Martínez-Frías, J., Smellie, J.L., Rey, J., and Maestro, A. (2004) Evidence for hydrothermal venting and sediment volcanism discharged after recent short-lived volcanic eruptions at Deception Island, Bransfield Strait, Antarctica. Mar Geol 203:119-140.

Spalding, C., Fischer, W.W., and Laughlin, G. (2018) An Orbital Window into the Ancient Sun's Mass. Astrophys J 869:L19.

Squyres, S.W. and Kasting, J.F. (1994) Early Mars: how warm and how wet? Science 265:744-749.

Stetter, K.O. (1999) Extremophiles and their adaptation to hot environments. FEBS Lett 452:22-25.

Stieglmeier, M., Klingl, A., Alves, R.J.E., Rittmann, S.K.M.R., Melcher, M., Leisch, N., and Schleper, C. (2014) Nitrososphaera viennensis gen. nov., sp. nov., an aerobic and mesophilic, ammonia-oxidizing archaeon from soil and a member of the archaeal phylum Thaumarchaeota. Int J Syst Evol Microbiol 64:2738-2752.

Van Der Meer, M.T.J., Schouten, S., Rijpstra, W.I.C., Fuchs, G., and Sinninghe Damsté, J.S. (2001) Stable carbon isotope fractionations of the hyperthermophilic crenarchaeon $\mathrm{Me}$ tallosphaera sedula. FEMS Microbiol Lett 196:67-70.

Van Kranendonk, M.J., Deamer, D.W., and Djokic, T. (2017) Life Springs. Sci Am 317:28-35.
Vogt, G., Woell, S., and Argos, P. (1997) Protein thermal stability, hydrogen bonds, and ion pairs. J Mol Biol 269:631-643.

Wang, S., Hou, W., Dong, H., Jiang, H., Huang, L., Wu, G., Zhang, C., Song, Z., Zhang, Y., Ren, H., Zhang, J., and Zhang, L. (2013) Control of temperature on microbial community structure in hot springs of the Tibetan Plateau. PLoS One 8:e62901.

Wilson, L. and Head, J.W. (2007) Heat transfer in volcano-ice interactions on Earth. Ann Glaciol 45:83-86.

Yabe, S., Sakai, Y., Abe, K., and Yokota, A. (2017) Diversity of Ktedonobacteria with Actinomycetes-like morphology in terrestrial environments. Microbes Environ 32:61-70.

Yang, Y.-L., Yang, F.-L., Jao, S.-C., Chen, M.-Y., Tsay, S.-S., Zou, W., and Wu, S.-H. (2006) Structural elucidation of phosphoglycolipids from strains of the bacterial thermophiles Thermus and Meiothermus. J Lipid Res 47:1823-1832.

Zhang, H., Sekiguchi, Y., Hanada, S., Hugenholtz, P., Kim, H., Kamagata, Y., and Nakamura, K. (2003) Gemmatimonas aurantiaca gen. nov., sp. nov., a Gram-negative, aerobic, polyphosphate-accumulating micro-organism, the first cultured representative of the new bacterial phylum Gemmatimonadetes phyl. nov. Int J Syst Evol Microbiol 53:1155-1163.

Zhang, H., Brankovics, B., Van Der Lee, T.A.J., and Waalwijk, C. (2016) A single-nucleotide-polymorphism- based genotyping assay for simultaneous detection of different carbendazim-resistant genotypes in the Fusarium graminearum species complex. PeerJ 4:e2609.

Address correspondence to: María Ángeles Lezcano Department of Molecular Evolution Centro de Astrobiología (CSIC-INTA) Torrejón de Ardoz, Madrid 28850 Spain

E-mail: mangeles.lezcano@gmail.com

Submitted 18 December 2018 Accepted 15 June 2019

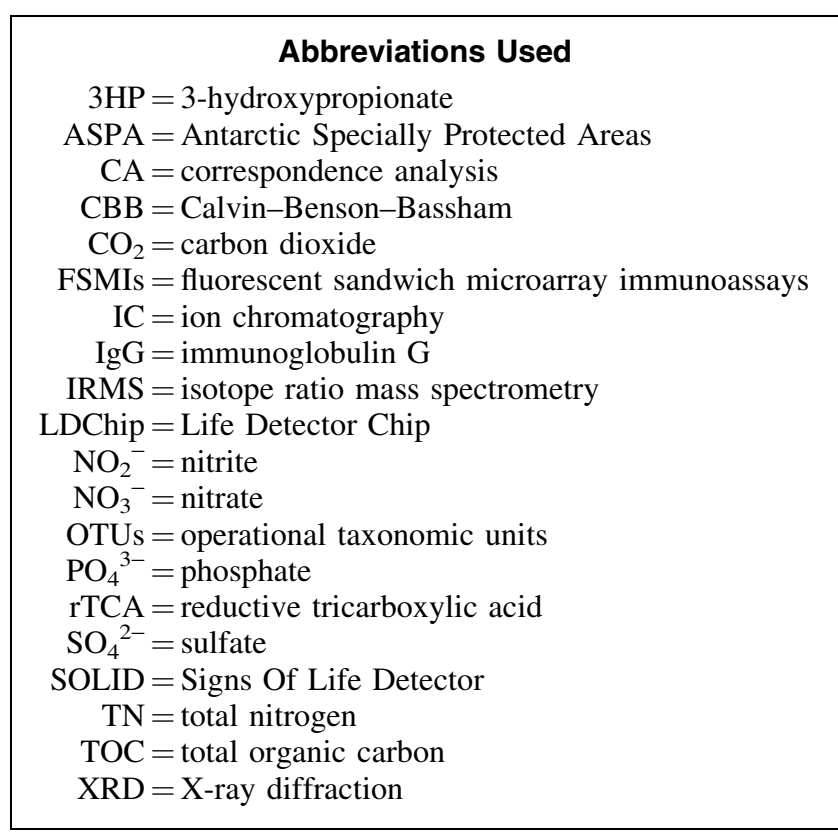

